\title{
Linarin prevents LPS-induced acute lung injury by suppressing oxidative stress and inflammation via inhibition of TXNIP/NLRP3 and NF-kB pathways
}

\author{
XIANG HAN, YI-CHEN WU, MIN MENG, QING-SONG SUN, SU-MIN GAO and HONG SUN \\ Department of Emergency, The Affiliated Huaian No. 1 People's Hospital of Nanjing Medical University, \\ Huai'an, Jiangsu 223300, P.R. China
}

Received April 28, 2017; Accepted May 9, 2018

DOI: $10.3892 / \mathrm{ijmm} .2018 .3710$

\begin{abstract}
Acute lung injury (ALI) is an important cause of morbidity and mortality for critically ill patients, and linarin (LR) may be a potential treatment for ALI as it reportedly has antioxidant, anti-inflammatory and apoptotic-regulating activity. In the present study, the authors report that saline and LR $(12.5,25$ and $50 \mathrm{mg} / \mathrm{kg})$ were applied to male C57BL/6 mice via gavage. Then, mice were intratracheally injected with either saline or lipopolysaccharide (LPS). LR-pretreatment attenuated LPS-induced ALI and platelet activation and reduced CD41 expression levels and neutrophil platelet aggregates. Additionally, LPS-triggered pulmonary myeloperoxidase activity and neutrophil infiltration in lung tissues, and this was eliminated by LR dose-dependently. Furthermore, LPS-induced oxidative stress and pro-inflammatory cytokine release were downregulated by LR by inhibiting thioredoxin-interacting protein and nuclear factor- $\kappa \mathrm{B}$ signaling pathways, including their downstream and upstream signals, such as xanthine oxidase, NLR family WHAT, pyrin domain-containing 3 (NLRP3), apoptosis-associated speck-like protein containing a C-terminal caspase recruitment domain (ASC), caspase-1, I $\mathrm{B}$ kinase- $\alpha$ (IKK- $\alpha$ ) and I $\mathrm{B} \mathrm{B} \alpha$. Moreover, in LPS-induced mice, the mitogen-activated protein kinase pathway was inactivated by LR. In vitro, LR reduced LPS-induced inflammation and oxidative stress, which was linked to reduction of ROS. In conclusion, LR pretreatment may be protective against LPS-induced ALI.
\end{abstract}

\section{Introduction}

Acute lung injury (ALI) and acute respiratory distress syndrome (ARDS) are life-threatening diseases induced by severe sepsis, severe bacterial pneumonia, trauma and burns $(1,2)$. Although

Correspondence to: Dr Hong Sun, Department of Emergency, The Affiliated Huaian No. 1 People's Hospital of Nanjing Medical University, Huai'an, Jiangsu 223300, P.R. China

E-mail: sunhong2017js@163.com

Key words: acute lung injury, linarin, oxidative stress, inflammation, TXNIP and nuclear factor- $\kappa \mathrm{B}$ advances have been made in understanding the pathophysiology of ALI and ARDS, there is no effective therapeutic strategy for treating either (3). Various molecular mechanisms are associated with the pathogenesis and progression of ALI, including oxidative stress and inflammatory responses (4). ALI is characterized by extreme inflammation, excessive neutrophil infiltration into the lung tissues, release of pro-inflammatory cytokines, and lung endothelial and epithelial injuries, resulting in edema and gas exchange deterioration $(5,6)$.

Reactive oxygen species (ROS)-induced oxidative stress contributes to ALI development (7) via stimulating TXNIP/NLRP3, nuclear factor (NF)- $\kappa \mathrm{B}$ and mitogen-activated protein kinase (MAPK) signaling pathways (8). TXNIP/NLRP3 activation is linked to ALIand TXNIP blocks antioxidant function; its overexpression has been observed in diverse diseases $(9,10)$. Accumulating evidence indicates that the NLRP3 inflammasome initiates the innate immunity and promotes inflammatory responses (11). Importantly, TXNIP links oxidative stress to NLRP3 activation in an ROS-sensitive manner (12). The process accelerates the secretion of pro-inflammatory cytokines, including tumor necrosis factor (TNF)- $\alpha$, interleukin (IL)-1 $\beta$ and IL-6, which are associated with NF- $\kappa$ B activity, eventually contributing to ALI (13). MAPKs are implicated in cellular inflammatory processes in response to oxidative stress (14).

LR (LR; acacetin-7-O- $\beta$-D-rutinoside) is a natural flavonoid glycoside abundant in various vegetables and fruits (15). Plants containing LR have been reportedly used to treat inflammatory diseases, cancer and hypertension $(16,17)$. LR alleviates LPS-induced cytokine production in a murine macrophage cell line (18). Recently, LR was reported to have antioxidant activity associated with enhancement of nuclear factor-erythroid 2-related factor 2 (Nrf2). LR activated Nrf2 activation to reduce ROS generation, inhibiting ischemia-reperfusion injury (19). Thus, LR may have potential for use in the treatment of ALI.

The current study reports that LPS induced ALI, as evidenced by platelet activation, inflammation and oxidative stress via activating NF- $\mathrm{B}$ and TXNIP/NLRP3 pathways, was suppressed by linarin partly via suppressing $N F-\kappa B$ and TXNIP/NLRP3, and by potentiating Nrf2. Therefore, LR pretreatment may prevent ALI-induced by LPS in vitro and in vivo. 


\section{Materials and methods}

Animals and treatment. A total of 100 male C57BL/6 mice (6-8 weeks old, weighing, 18-20 g) were purchased from The Animal Center of Nanjing Medical University (Nanjing, China), and provided with food and water ad libitum and kept in climate-controlled quarters with a $12 \mathrm{~h}$ light/dark cycle with food and water in cages under the germ-free conditions at a temperature of $25^{\circ} \mathrm{C}$. The mice were housed for a minimum of one week for environmental adaptation prior to experimentation. All procedures were in accordance with the Regulations of Experimental Animal Administration issued by the Ministry of Science and Technology of the People's Republic of China, and before the animal experiments were performed, the procedures were approved by the Research Ethical Committee of Huai'an First People's Hospital, Nanjing Medical University (Nanjing, China).

C57BL/6 mice were randomly divided into 5 groups as follows ( $\mathrm{n}=20$ in each group): i) Control (Con); ii) LPS treatment (LPS); iii) Low dose of LR treatment (LPS treatment + oral gavage of $12.5 \mathrm{mg} / \mathrm{kg}$ LR for 3 days, LD-LR); iv) Medium dose of LR treatment (LPS treatment + oral gavage of $25 \mathrm{mg} / \mathrm{kg} \mathrm{LR}$ for 3 days, MD-LR); and v) High dose of LR treatment (LPS treatment + oral gavage of $50 \mathrm{mg} / \mathrm{kg} \mathrm{LR}$ for 3 days, HD-LR). The mice from the control and LPS groups received an equal volume of normal saline $(0.3 \mathrm{ml})$ instead of LR. LR was purchased from Fanke Biotech Fanke Biotech Co., Ltd. (http://fanketech.biomart.cn, FA-1701, HPLC $\geq 98 \%$, Shanghai, China). At $3 \mathrm{~h}$ following drug administration on the third day, the mice were slightly anesthetized with inhalation of diethyl ether ( $1 \mathrm{ml}$ diethyl ether dipping cotton balls), and $10 \mu \mathrm{g}$ LPS in $50 \mu \mathrm{l}$ PBS was intranasally instilled to induce lung injury. The mice in the control group were given $50 \mu \mathrm{l}$ normal saline in the absence of LPS. A total of $24 \mathrm{~h}$ later for LPS treatment, all mice were sacrificed through an intraperitoneal injection of $50 \mathrm{mg} / \mathrm{kg}$ pentobarbital (Sigma-Aldrich; Merck KGaA, Darmstadt, Germany) and bronchoalveolar lavage fluid (BALF) and lung tissue samples were harvested for further researches. The ratios of lung wet/dry weight were measured by dividing the wet weight by the dry weight. The middle lobe of the right lung was excised and the wet weight was recorded. Then, the lung was placed in an incubator for $24 \mathrm{~h}$ at $80^{\circ} \mathrm{C}$ to obtain the dry weight.

Cells and culture. Thehuman lung epithelial cell line, BEAS-2B, was purchased from Shanghai Haoran Biological Technology Co., Ltd. (Shanghai, China) and kept in DMEM/F12 containing $1 \%$ penicillin/streptomycin and 10\% FBS (Hyclone; GE Healthcare Life Sciences, Chalfont, UK). Cells were then cultured in a humidified atmosphere with $5 \% \mathrm{CO}_{2}$ and $95 \%$ humidity at $37^{\circ} \mathrm{C}$ in an incubator.

Biochemical assays. Superoxide dismutase (SOD, A001-3), catalase (CAT, A007-1-1) and glutathione peroxidase (GPx, A005) activities, as well as malondialdehyde (MDA, A003-1) levels in lung tissue sample were determined by commercially available kits (Nanjing Jiancheng Bioengineering Institute, Nanjing, China) following the manufacturer's instructions. $\mathrm{H}_{2} \mathrm{O}_{2}$ levels in lung tissues were measured using a hydrogen peroxide assay kit, (Beyotime Institute of Biotechnology, Haimen, China) following the manufacturer's instructions. $\mathrm{O}_{2}{ }^{-}$in lung tissues was measured through lucigenin chemiluminescence method. Briefly, lung tissues of mice under different conditions were weighed and homogenized in a homogenization buffer using HEPES and EDTA. Following centrifugation $\left(1,000 \mathrm{x} \mathrm{g}\right.$ at $4^{\circ} \mathrm{C}$ for $\left.10 \mathrm{~min}\right)$, an aliquot of the supernatant was incubated with $5 \mu \mathrm{M}$ lucigenin in Krebs-HEPES buffer. Light emission was measured with a Tecan Infinite 200 (Tecan Group AG, Männedorf, Switzerland). Specificity for $\mathrm{O}_{2}{ }^{-}$was evaluated by adding SOD $(350 \mathrm{U} / \mathrm{ml})$ to the incubation medium. BCA Protein Quantitative Analysis kit (Thermo Fisher Scientific, Inc., Waltham, MA, USA) was used to measure the protein concentration.

Assessment of arterial blood gas. A total of 40 male C57BL/6 mice (6-8-weeks old, 18-20 g weight) were pretreated with LR $(0,12.5,25$ and $50 \mathrm{mg} / \mathrm{kg})$ for 3 days by gavage orally. At $3 \mathrm{~h}$ following drug administration on the third day, the mice were slightly anesthetized with inhalation of diethyl ether (1 $\mathrm{ml}$ diethyl ether dipping cotton balls), and $10 \mu \mathrm{g}$ LPS in $50 \mu 1$ PBS was instilled intranasally to induce lung injury. The mice in the control group were given $50 \mu \mathrm{l}$ of normal saline without LPS. At $24 \mathrm{~h}$ following LPS treatment, the mice were sacrificed by an intraperitoneal injection of pentobarbital (50 mg/kg; Sigma-Aldrich; Merck KGaA). The retro-orbital blood samples $(1 \mathrm{ml})$ from each mouse was collected and used to measure the parameters of arterial blood gas, including blood hemoglobin concentration $(\mathrm{Hgb}), \mathrm{pH}, \mathrm{HCO}_{3}$, partial pressure of oxygen $\left(\mathrm{PO}_{2}\right)$, partial pressure of carbon dioxide $\left(\mathrm{PCO}_{2}\right)$, lactate (LAC) and base excess (BE) using Hitachi 8500 automatic analyzer (Hitachi, Ltd., Tokyo, Japan).

Immunofluorescence analysis. For measurement of CD41 using immunofluorescence staining was performed. Briefly, the frozen sections of lung tissue samples were washed with PBS twice and then were blocked with $1 \%$ bovine serum albumin at room temperature for $30 \mathrm{~min}$. Then the cells and heart tissue samples were incubated overnight with rabbit anti-CD41 primary antibody (ab63983, 1:50; Abcam, Cambridge, UK). After being washed with PBS for three times, the samples were performed with goat anti-rabbit secondary antibody conjugated to Alexa Fluor 647 (A0468, 1:400) and goat anti-rabbit secondary antibody conjugated to Alexa Fluor 488 (A0423, 1:400) (both from Beyotime Institute of Biotechnology) for $1 \mathrm{~h}$ under dark conditions. Then, the cells were counterstained with DAPI (Beyotime Institute of Biotechnology) for $15 \mathrm{~min}$, and the tissue sections were analyzed using an immunofluorescence microscope. Three slides per experimental condition are repeated three times.

Bronchoalveolar lavage fluid $(B A L F)$ isolation and analysis. BALF was collected by flushing the left lung $(0.4 \mathrm{ml}$, three times). Total BALF cells were measured using a hemocytometer. A part of the BALF was centrifuged for $5 \mathrm{~min}$ at $92 \mathrm{x} \mathrm{g}$ by cytospin on a microscopic slide at $4^{\circ} \mathrm{C}$. BALF cells were stained using Giemsa at room temperature for $10 \mathrm{~min}$. The rest of BALF was filtrated through a $0.22 \mu \mathrm{m}$ pore-size filter and then stored at $-80^{\circ} \mathrm{C}$ for protein and cytokine detection, while the cell pellet was resuspended in PBS for counting the neutrophils. The concentration of BALF protein was measured using BCA Protein Assay kit. 
Measurement of cytokine levels in BALF. IL-1 $\beta$ (cat. no. MLB00C), TNF- $\alpha$ (cat. no. MTA00B), IL-10 (cat. no. DY417), IL-6 (cat. no. M6000B), cyclooxygenase (COX)2 (cat. no. DYC4198-2), monocyte chemotactic protein 5 (MCP-5; cat. no. MCC120), macrophage inflammatory protein-1 $\alpha$ (MIP-1 $\alpha$ ) (cat. no. MMA00), thromboxane B2 (TXB2; cat. no. KGE011) and myeloperoxidase (MPO; cat. no. DY3667) levels in BALF were measured using ELISA kits (R\&D System Inc., Minneapolis, MN, USA). The procedures were performed following the manufacturer's instructions.

Immunohistochemical analysis. Histopathological evaluation was performed on mice not subjected to BAL. Lungs were inflated and fixed with $10 \%$ buffered formalin for $48 \mathrm{~h}$ at room temperature and embedded in paraffin (Beyotime Institute of Biotechnology). Tissue sections were cut at $4 \mu \mathrm{m}$ thickness and stained with hematoxylin and eosin (H\&E) following the regular staining method. The sections were deparaffinized in xylene for $10 \mathrm{~min}$. Then, the slides were re-hydrated in absolute alcohol for 5 min each, followed by $95 \%$ alcohol for 2 min and $70 \%$ alcohol for 2 min and then washing with water. Subsequently, the sections were stained in Harris hematoxylin solution for $8 \mathrm{~min}$ at room temperature, followed by washing under a running water for $5 \mathrm{~min}$. The slides were then differentiated in $1 \%$ acid alcohol for $30 \mathrm{sec}$, followed by washing using running tap water for $1 \mathrm{~min}$. Then, the sections were subjected to bluing in $0.2 \%$ ammonia water or saturated lithium carbonate solution for $30 \mathrm{sec}$ at room temperature, followed by washing under running water for $5 \mathrm{~min}$ and rinsing in $95 \%$ alcohol. The sections were counterstained in eosin-phloxine solution for $30 \mathrm{sec}$ at room temperature; the slides were dehydrated via $95 \%$ alcohol for $5 \mathrm{~min}$ and cleared in xylene for $5 \mathrm{~min}$. Finally, the sections were mounted with xylene-based mounting medium. The severity of injury was judged based on the following criteria: 0 , no injury; 1 , injury to $25 \%$ of the field; 2 , injury to $50 \%$ of the field; 3 , injury to $75 \%$ of the field; and 4 , diffuse injury. The ultimate score was obtained by adding the aforementioned scores. Immunohistochemistry was performed using the paraffin-embedded tissue sections at $4 \mu \mathrm{m}$ thickness mounted on glass slides. The slides were then deparaffinized and rehydrated. Then, the lung sections were incubated with primary antibodies against mouse TXNIP (ab210826, dilution: 1:200) and xanthine oxidase (XO, ab176165, dilution: 1:200) (both from Abcam), and then with biotin secondary antibodies (B3640; Sigma-Aldrich; Merck KGaA) at room temperature for $30 \mathrm{~min}$. The number of XO-, and TXNIP-positive cells in lung sections was counted using Pax-it software (version 6; Paxcam, Villa Park, IL, USA).

Flow cytometry assays. Whole blood samples from mice were collected and maintained in acid citrate dextrose (Sigma-Aldrich; Merck KGaA). Anti-CD11b eFluor450 (1:100), anti-CD41-allophycocyanin (1:100) (both from eBioscience; Thermo Fisher Scientific, Inc.), anti-Ly6C-PE (1:100; BD Biosciences, Franklin Lakes, NJ, USA) and anti-Ly6G-phycoerythrin (1:100; BD Biosciences) were used to detect leukocyte and platelets antigens. Samples were examined with an LSRII flow cytometer (BD Biosciences) and analyzed using FCS express software (version 3.0, De Novo Software, Glendale, CA, USA). Neutrophils and monocytes were gated through their forward- and side-scatter characteristics and through their $\mathrm{Ly}-6 \mathrm{G}^{+} / \mathrm{CD} 11 \mathrm{~b}^{+}$(neutrophil) and $\mathrm{Ly}-6 \mathrm{G}^{-} / \mathrm{CD} 11 \mathrm{~b}^{+} / \mathrm{Ly}-6 \mathrm{C}^{+}$(monocyte) expression pattern. Platelet-neutrophil and platelet-monocyte aggregates were calculated using CD41 antibody staining.

ROS generation. Intracellular ROS generation regulated by LPS, ATP and N-Acetylcysteine (NAC) (both from Sigma-Aldrich; Merck KGaA) was assessed by calculating the fluorescence intensity of 2',7'-dichlorofluorescein diacetate oxidized product (Molecular Probes; Thermo Fisher Scientific, Inc.). The relative fluorescence intensity of oxidized product of $2^{\prime}, 7^{\prime}$-dichlorofluorescein diacetate, was tested at an excitation wavelength of $485 \mathrm{~nm}$ and an emission wavelength of $530 \mathrm{~nm}$ using a Quantus ${ }^{\mathrm{TM}}$ Fluorometer (Promega Corporation, Madison, WI, USA). All cells after various treatments were harvested for ROS assessment through ROS Fluorescent Probe-DCF (Vigorous Biotechnology Beijing Co., Ltd., Beijing, China;http://www.vigorousbiol.com/) according to the manufacturer's instructions.

Reverse transcription-quantitative ( $R T-q P C R)$ analysis. Lung samples were immediately acquired from mice following sacrifice and were used in the extraction of total RNA using TRIzol reagent (Invitrogen; Thermo Fisher Scientific, Inc.). Subsequently, the RNA was purified using the RNeasy mini kit following the manufacturer's instructions (Qiagen,Inc., Valencia, CA, USA). cDNA was synthesized using SuperScript II RNase H-Reverse Transcriptase (Invitrogen; Thermo Fisher Scientific, Inc.). SYBR-Green Master Mix (Applied Biosystems; Thermo Fisher Scientific, Inc.; $10 \mu 1$ Master Mix, $0.5 \mu 1$ forward primer,

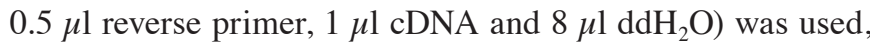
and qPCR was performed in accordance with the manufacturer's protocol. The 7000 Sequence Detection system (Applied Biosystems; Thermo Fisher Scientific, Inc.) was applied to perform qPCR analysis. The specific sequences of primers used in the study for gene amplification were shown in Table I. The cycling conditions (33 cycles) were exhibited as followings: $95^{\circ} \mathrm{C}$ for $5 \mathrm{~min}, 95^{\circ} \mathrm{C}$ for $10 \mathrm{sec}, 60^{\circ} \mathrm{C}$ for $30 \mathrm{sec}, 95^{\circ} \mathrm{C}$ for $15 \mathrm{sec}$, $60^{\circ} \mathrm{C}$ for $60 \mathrm{sec}$ and $95^{\circ} \mathrm{C}$ for $15 \mathrm{sec}$. The expression levels of targeting mRNAs were normalized to that of housekeeping gene of GAPDH using the $2^{-\Delta \Delta C q}$ method (20).

Western blot analysis. The total protein of lung tissue samples and cells was extracted by addition of cold lysis buffer [10 $\mathrm{mM}$ Tris-HCl, 1 mMEDTA, and $250 \mathrm{mM}$ sucrose, $\mathrm{pH} 7.4$, containing $15 \mu \mathrm{g} / \mathrm{ml}$ aprotinin, $5 \mu \mathrm{g} / \mathrm{ml}$ leupeptin, $0.1 \mathrm{mM}$ phenylmethanesulfonyl fluoride (PMSF), $1 \mathrm{mM} \mathrm{NaF}$, and $1 \mathrm{mM} \mathrm{Na}_{3} \mathrm{VO}_{4}$ (Beyotime Institute of Biotechnology)] for $50 \mathrm{~min}$ at $4^{\circ} \mathrm{C}$. Then, the lysates were centrifuged at $12,000 \mathrm{x}$ g for $20 \mathrm{~min}$ at $4^{\circ} \mathrm{C}$. The soluble protein concentrations in the lysates were assessed using a BCA Protein Assay kit. Next, $40 \mu \mathrm{g}$ total protein was separated on a $12 \%$ SDS-PAGE gel and was transferred onto a polyvinylidene difluoride membrane. Then, the membrane was blocked in $5 \%$ dried milk for $2 \mathrm{~h}$ at room temperature and was incubated with specific primary antibodies at $4^{\circ} \mathrm{C}$ overnight. The membrane was then washed with TBS Tween-20 (TBST, containing $0.1 \%$ Tween-20) for three times, followed by incubation with a horseradish peroxidase-conjugated secondary antibody (A0208; Beyotime Institute of Biotechnology) at room temperature for $2 \mathrm{~h}$. Following another round of washing 
Table I. Primer sequences of RT-PCR test.

\begin{tabular}{lll}
\hline Gene & \multicolumn{1}{c}{ Forward primers $\left(5^{\prime}-3^{\prime}\right)$} & Reverse primers $\left(5^{\prime}-3 '\right)$ \\
\hline GAPDH & CGGTCCATAGCAAAACGAGG & TACACTACGCAGCCAACACACC \\
iNOS & TTGGTGGAAGGCAGTTGAGG & CAGCAGGTAGACAAACCATTCA \\
MCP-5 & ATGCCGAGGAACAGATATCTA & CGACCATATCGCACGAGTGCA \\
TNF- $\alpha$ & AGCACACAAGTGGCACAACG & CATGCGGTCGTAGTCCATAAT \\
MIP-1 $\alpha$ & CAGCAGGCAGCACGTGTCGC & CTTCAACATATGTTAACAGTAC \\
IL-1 $\beta$ & GAAGTATGCTTAGCCAGTAAG & GAGCGTCGCAATTGTTGTGG \\
IL-10 & CGATCTGCTATCCCACGGA & CTGACCAGCCATAGCCAGA \\
SOD1 & GGAGCACTGAACGCACAGA & CTACGGAGATTCAAACTCGTG \\
COX2 & CCGCATTCTGGTATAACGAACA & ACCGAGAAGCCAGCACCAT \\
IL-6 & ATTCGGCAACCGAGATATAGA & TGACAACTAGAACGATCCAACC \\
SOD2 & GCATAACTCGAGAACTTACGC & ACTACATTATCGGGTCGGAGTA \\
CAT & GAGGACTATATCTTCTCGAC & GAATGGTCCCTCGCACTCG \\
GCLC & GTGACCCTTAACTTGAGAG & AGGACGCAGATCGGACCAACG \\
Ly6G & GCATCTACGTACAGGACCG & AGTCGGTGATGACAGTATGAG \\
CD41 & ATATCGGCCTATACTCGAT & CAGGATGCTAGTCGTAATGTA
\end{tabular}

with TBST, the membrane was then developed using enhanced chemiluminescence (Thermo Fisher Scientific, Inc.). The antibodies used in the study are shown below. The staining intensity of the bands was quantitated by densitometry through ImageJ software (version 1.49, National Institute of Health, Bethesda, MD, USA). Triplicate experiments with at least triplicate samples were performed. The primary antibodies: Rabbit anti-NLRP3 (1:1,000, cat. no. 15101), rabbit anti-ASC (1:1,000, cat. no. 67824) (both from Cell Signaling Technology, Inc., Danvers, MA, USA), rabbit anti-caspase-1 (1:1,000, ab1872), rabbit anti-Nrf2 (1:1,000, ab31163) (both from Abcam), rabbit anti-HO-1 (1:1,000, cat. no. 70081), rabbit anti-p-ERK1/2 (1:1,000, cat. no. 4370; Cell Signaling Technology, Inc.), rabbit anti-ERK1/2 (1:1,000, ab17942; Abcam), rabbit anti-p-JNK (1:1,000, cat. no. 9255), rabbit anti-JNK (1:1,000, \#9252) (both from Cell Signaling Technology, Inc.), rabbit anti-XO (1:1,000, ab109235), rabbit anti-TXNIP (1:1,000, ab188865) (both from Abcam), rabbit anti-p-p38 (1:1,000, cat. no. 9211), rabbit anti-p38 (1:1,000, cat. no. 8690), rabbit anti-p-IKK $\alpha(1: 1,000$, cat. no. 2697), rabbit anti-IKK $\alpha(1: 1,000$, cat. no. 2682) (all from Cell Signaling Technology, Inc.), anti-NF- $\mathrm{B}(1: 1,000$, ab19870), rabbit anti-p-NF- $\mathrm{B}$ (1:1,000, ab86299), rabbit

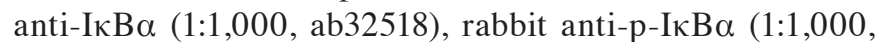
ab24783) (all from Abcam), rabbit and anti-GAPDH (1:500, sc-293335, Santa Cruz Biotechnology, Inc., Dallas, TX, USA). Immunoreactive bands were visualized by ECL Immunoblot Detection system (Pierce; Thermo Fisher Scientific, Inc.) and exposed to Kodak (Rochester, NY, USA) X-ray film. Every protein expression levels will be defined as grey value (ImageJ, Version 1.4.2b, National Institutes of Health) and standardized to housekeeping gene of GAPDH and expressed as a fold of control. All experiments were performed in triplicate and done three times independently.

Statistical analysis. Data are expressed as the means \pm standard error of the mean. Treated cells, tissues and the corresponding controls were compared using GraphPad Prism (GraphPad
Software, Inc., La Jolla, CA, USA) by a one-way analysis of variance with Dunn's least significant difference tests. $\mathrm{P}<0.05$ was considered to indicate a statistically significant difference.

\section{Results}

LR attenuates LPS-induced ALI in mice. Platelets were counted and pulmonary edema was measured with a ratio of lung wet to dry weight. Fig. 1A presents an increased wet/dry ratio in the LPS-treated group and LR reduced this in a dose-dependent manner. In addition, as shown in Table II, $\mathrm{PO}_{2}, \mathrm{HCO}_{3}, \mathrm{Hgb}, \mathrm{BE}$ and $\mathrm{PH}$ increased in the LPS-treated group and these were reduced in LR-pretreated groups. In contrast, LR pretreatment upregulated LAC reduced by LPS but $\mathrm{PCO}_{2}$ was not significantly different in mice treated as indicated. Arterial blood gas analysis indicated that LR may be protective in LPS-induced ALI in mice. Thromboxane A2 is a marker of platelet activation, and is rapidly hydrolyzed to its inactive stable metabolite, TXB2 (21). Plasma TXB2 were upregulated in mice challenged with LPS and LR treatment dramatically diminished TXB2 expression (Fig. 1B). H\&E staining scores were high following LPS treatment indicating lung damage, but this was reversed by LR administration in a dose-dependent manner (Fig. 1C). CD41, a specific platelet marker, can be measured to confirm sequestration of platelets in pulmonary capillaries (22). Platelet activation is involved in ALI $(23,24)$ and immunofluorescence analysis revealed that LR dose-dependently reduced CD41 expression in lung tissues of mice treated with LPS (Fig. 1D). Moreover, RT-qPCR analysis verified downregulated CD41 in LPS-treated lung tissue samples of mice with ALI (Fig. 1E). Thus, LR may have protective effects against LPS-induced ALI.

LR inhibits LPS-induced inflammation infiltration in BALF. BALF cytology data show that alveoli undergo dramatic shifts after ALI (25). BAL total protein calculated as an indicator of lung permeability was elevated after LPS instillation (26). 
Table II. Blood gas analysis in mice.

\begin{tabular}{lrrrrr}
\hline Indexes & \multicolumn{1}{c}{ Con } & \multicolumn{1}{c}{ LPS } & LC-LR & MC-LR & HC-LR \\
\hline $\mathrm{PO}_{2}(\mathrm{mmHg})$ & $71.3 \pm 1.2$ & $88.9 \pm 2.4^{\mathrm{b}}$ & $85.1 \pm 1.7$ & $80.3 \pm 1.9^{\mathrm{d}}$ & $78.5 \pm 2.2^{\mathrm{d}}$ \\
$\mathrm{PCO}_{2}(\mathrm{mmHg})$ & $37.6 \pm 1.3$ & $37.9 \pm 1.9$ & $38.1 \pm 1.6$ & $38.4 \pm 1.5$ & $38.1 \pm 1.8$ \\
$\mathrm{HCO}_{3}(\mathrm{mmol})$ & $16.8 \pm 0.4$ & $22.9 \pm 1.0^{\mathrm{a}}$ & $20.1 \pm 0.8$ & $18.6 \pm 0.9^{\mathrm{d}}$ & $17.8 \pm 0.6^{\mathrm{d}}$ \\
$\mathrm{LAC}(\mathrm{mM})$ & $3.8 \pm 0.2$ & $2.4 \pm 0.4^{\mathrm{b}}$ & $2.9 \pm 0.2^{\mathrm{d}}$ & $3.1 \pm 0.3^{\mathrm{d}}$ & $3.4 \pm 0.4^{\mathrm{e}}$ \\
$\mathrm{Hgb}(\mathrm{g} / \mathrm{dl})$ & $121.81 \pm 3.8$ & $148.36 \pm 4.2^{\mathrm{c}}$ & $135.85 \pm 4.8$ & $130.66 \pm 4.6^{\mathrm{d}}$ & $125.78 \pm 2.8^{\mathrm{e}}$ \\
$\mathrm{BE}(\mathrm{mEq} / \mathrm{l})$ & $-7.6 \pm 0.8$ & $-3.3 \pm 0.6^{\mathrm{b}}$ & $-4.1 \pm 0.9$ & $-5.6 \pm 1.0^{\mathrm{d}}$ & $-6.6 \pm 0.8^{\mathrm{d}}$ \\
$\mathrm{PH}$ & $7.08 \pm 0.02$ & $7.36 \pm 0.03^{\mathrm{a}}$ & $7.28 \pm 0.01$ & $7.13 \pm 0.03$ & $7.10 \pm 0.04^{\mathrm{d}}$
\end{tabular}

$\mathrm{PO}_{2}$, partial pressure of oxygen; $\mathrm{PCO}_{2}$, partial pressure of carbon dioxide; $\mathrm{HCO}_{3}^{-}$, bicarbonate level; LAC, lactate concentration; $\mathrm{BE}$, base excess; Hgb, hemoglobin concentration. ${ }^{\mathrm{a}} \mathrm{P}<0.05,{ }^{\mathrm{b}} \mathrm{P}<0.01$ and ${ }^{\mathrm{c}} \mathrm{P}<0.001$ vs. the Con group in the absence of any treatments. ${ }^{\mathrm{d}} \mathrm{P}<0.05$ and ${ }^{\mathrm{e}} \mathrm{P}<0.01$ vs. the LPS groups.

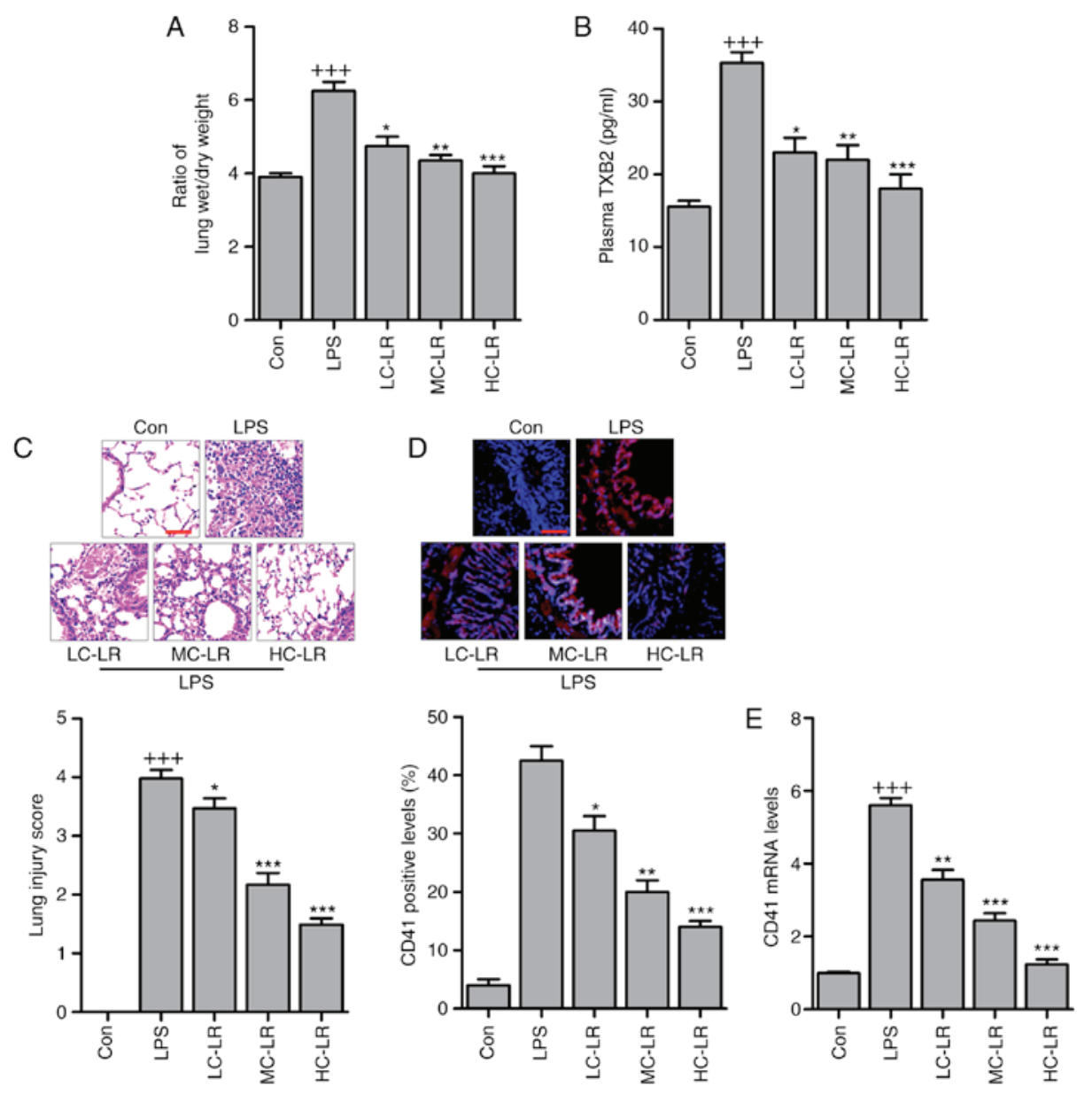

Figure 1. LR ameliorates the acute lung injury of mice with LPS induction. (A) The ratio of lung wet to dry weight was measured. (B) TXB2 levels in plasma were evaluated using ELISA method. (C) Representative images of hematoxylin and eosin staining of LPS-induced lung tissues treated with or without LR. Scale bar, $100 \mu \mathrm{m}$. (D) The immunofluorescence analysis of CD41 positive levels in lung tissue samples treated under various conditions, and the images were displayed. Scale bar, $100 \mu \mathrm{m}$. (E) Reverse transcription-quantitative polymerase chain reaction analysis was used to determine CD41 expression levels in LPS-induced lung tissues of mice administered with different doses of LR. Data are represented as mean \pm standard error of the mean of three independent experiments $(\mathrm{n}=6) .{ }^{+++} \mathrm{P}<0.001$ vs. the Con group in the absence of any treatments; ${ }^{*} \mathrm{P}<0.05,{ }^{* *} \mathrm{P}<0.01$ and ${ }^{* * * *} \mathrm{P}<0.001$ vs. the LPS groups. LPS, lipopolysaccharide; LR, linarin; Con, control; LC-LR, low concentration linarin; MC-LR, medium concentration linarin; HC-LR, high concentration linarin.

Mice given LR had reduced BAL protein compared to the LPS group (Fig. 2A). BAL cells were increased, indicating lung permeability, was markedly increased by LPS treatment, which was reduced by LR administration (Fig. 2B). In addition, BALF macrophages (MACs), BALF polymorphonuclear leukocytes
(PMNs) and lymphocytes were increased with LPS induction. However, LR treatment reduced MACs, PMNs and lymphocytes in BALF (Fig. 2C-E). MPO activity, a marker of neutrophil activation (Fig. 2F) was greater in LPS-treated samples compared to controls. MPO activity was reduced in LR-treated groups. 

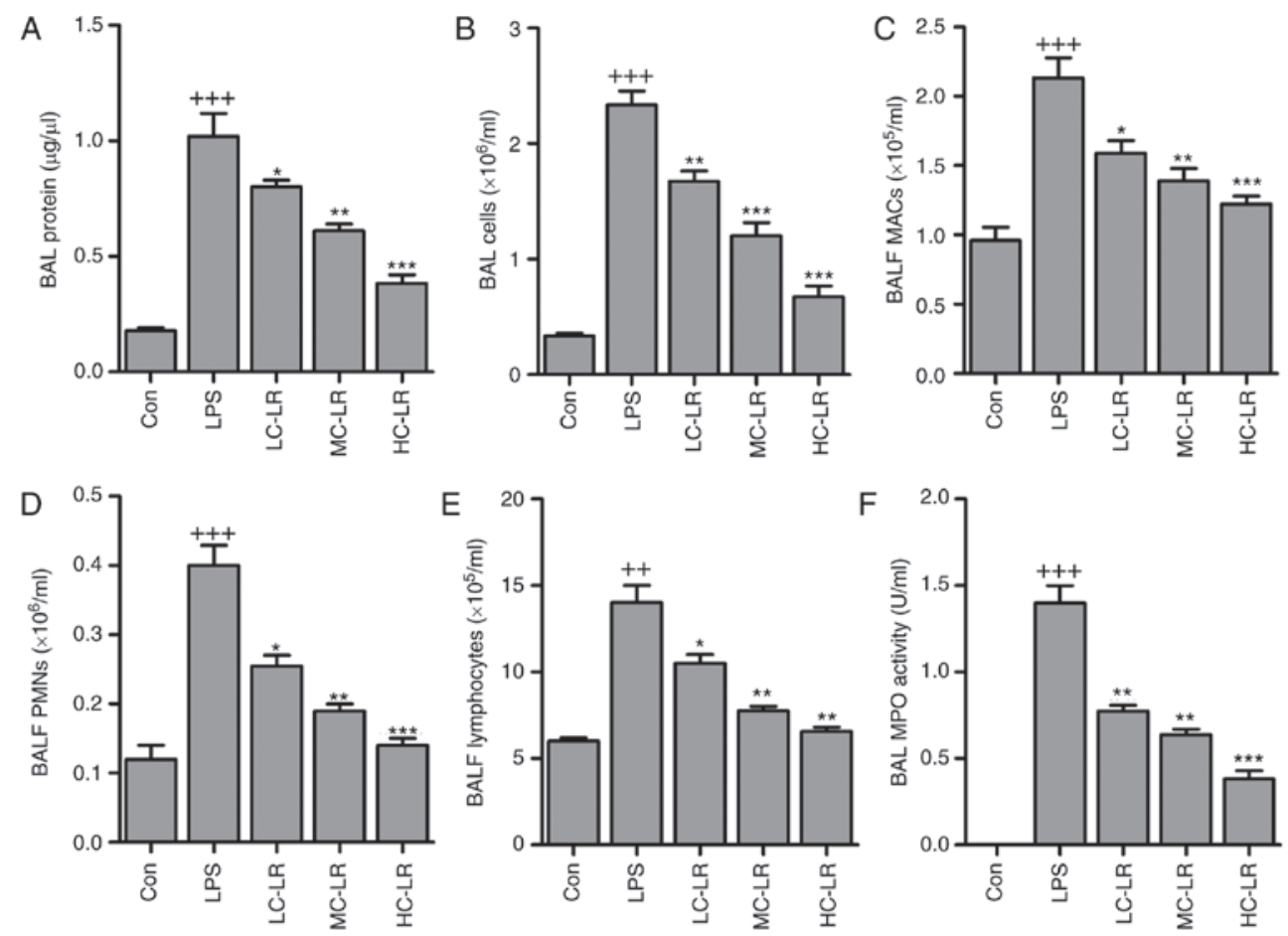

Figure 2. LR reduces LPS-induced inflammation infiltration in BALF of mice. (A) Bronchoalveolar lavage protein levels were evaluated. (B) Total BALF cells were evaluated. (C) The number of BALF macrophages (MACs) was measured. (D) The quantification of BALF polymorphonuclear leukocytes (PMNs) was exhibited. (E) The number of BALF lymphocytes was tested. (F) Pulmonary MPO activity was assessed. Data are represented as mean \pm standard error of the mean of three independent experiments $(\mathrm{n}=6) .{ }^{++} \mathrm{P}<0.01$ and ${ }^{+++} \mathrm{P}<0.001$ vs. the Con group in the absence of any treatments. ${ }^{*} \mathrm{P}<0.05,{ }^{* *} \mathrm{P}<0.01$ and ${ }^{* * * *} \mathrm{P}<0.001$ vs. the LPS groups. LR, linarin; BALF, bronchoalveolar lavage fluid; MPO, myeloperoxidase; LPS, lipopolysaccharide; Con, control; LC-LR, low concentration linarin; MC-LR, medium concentration linarin; HC-LR, high concentration linarin.

LR inactivates platelets in LPS-induced ALI. Antibodies against leukocyte-specific surface markers of Ly6G, Ly6C and $\mathrm{CD} 11 \mathrm{~b}$ were used to measure neutrophil-platelet aggregates (NPA) and monocyte-platelet aggregates (MPAs), defined as $\mathrm{Ly} 6 \mathrm{G}^{+} / \mathrm{CD} 1 \mathrm{~b}^{+} / \mathrm{CD}^{-} 1^{+}$and $\mathrm{Ly} 6 \mathrm{C}^{+} / \mathrm{CD} 11 \mathrm{~b}^{+} / \mathrm{CD} 41^{+}$, respectively. Whole blood extracted from mice had more NPA and MPA after LPS treatment and this was time-dependent. LR $(50 \mathrm{mg} / \mathrm{kg}$ ) considerably reduced the proportion of NPAs and MPAs after LPS-treatment for $48 \mathrm{~h}$ (Fig. 3A and B). NPAs in BAL were elevated after LPS induction and then reduced by LR (Fig. 3C). Furthermore, TXB2 in BAL was greater after LPS treatment and this was downregulated by LR dose-dependently (Fig. 3D). High expression of Ly6G induced by LPS was abolished following LR administration (Fig. 3E). Thus, LR can alleviate LPS-induced ALI via inactivating platelets. LPS treatment increased serum and BALF TNF- $\alpha$, IL-1 $\beta$, IL-6, MCP-5, MIP-1 $\alpha$ COX2 and IL-10 (Fig. 4) and LR administration reduced all of these except IL-10, which was enhanced, indicating an anti-inflammatory effect of LR.

MDA levels induced LPS were reduced after LR treatment (Fig. 5A). In addition, oxidative stress induced by LPS, as evidenced by elevated levels of $\mathrm{H}_{2} \mathrm{O}_{2}$ and $\mathrm{O}_{2}$. in lung tissue samples was suppressed by LR treatment, and SOD, CAT and GPx activity in lung tissue samples (Fig. 5B) were elevated by LPS, and LR treatment increased these levels even further suggesting antioxidant activity. RT-qPCR assays demonstrated that SOD2, SOD1, CAT and glutamate-cysteine ligase (GCLC) expression were enhanced with LPS induction and increased more with LR (Fig. 5C). LPS-triggered increased Nrf2 and HO-1 was augmented by LR dose-dependently (Fig. 5D).
Thus, LR exerts an antioxidant effect against LPS-induced ALI in vivo.

LR inhibits the TXNIP/NLRP3 signaling pathway in the lung tissues of mice exposed to LPS. The TXNIP/NLRP3 signaling pathway is involved in the progression of oxidative stress $(27,28)$. Therefore, immunohistochemical analysis was used to calculate $\mathrm{XO}$ and TXNIP in lung tissue samples. Fig. 6A and B show that XO and TXNIP were significantly induced by LPS compared to controls and LR administration reduced expression of XO and TXNIP. Fig. $6 \mathrm{C}$ also shows that LR can reduce LPS-induced increased expression of XO and TXNIP. Western blotting indicated that NLRP3, ASC and caspase-1 protein were markedly increased by LPS treatment, and decreased following LR administration (Fig. 6D). Thus, the TXNIP/NLRP3 pathway are involved in LR-modulated ALI induced by LPS.

LR impedes MAPK and NF- $\kappa B$ pathways in LPS-exposed mice with ALI. MAPKs (p38-MAPK, ERK1/2-MAPK and JNK-MAPK) are associated with oxidative stress (29). Fig. 7A shows that LPS increased phosphorylated p38, ERK1/2 and JNK, and LR considerably reduced this dose-dependently. Inflammation is key to LPS-induced ALI, so western blotting was used to measure the NF- $\kappa \mathrm{B}$ pathway, which is important for regulating the secretion of pro-inflammatory cytokines. Fig. 7B data show that LR reduced LPS-induced phosphorylation of IKK- $\alpha, \mathrm{I} \kappa \mathrm{B} \alpha$ and NF- $\kappa \mathrm{B}$, indicating LR can be used to reduce inflammation by inactivating the NF- $\kappa \mathrm{B}$ signaling pathway. 

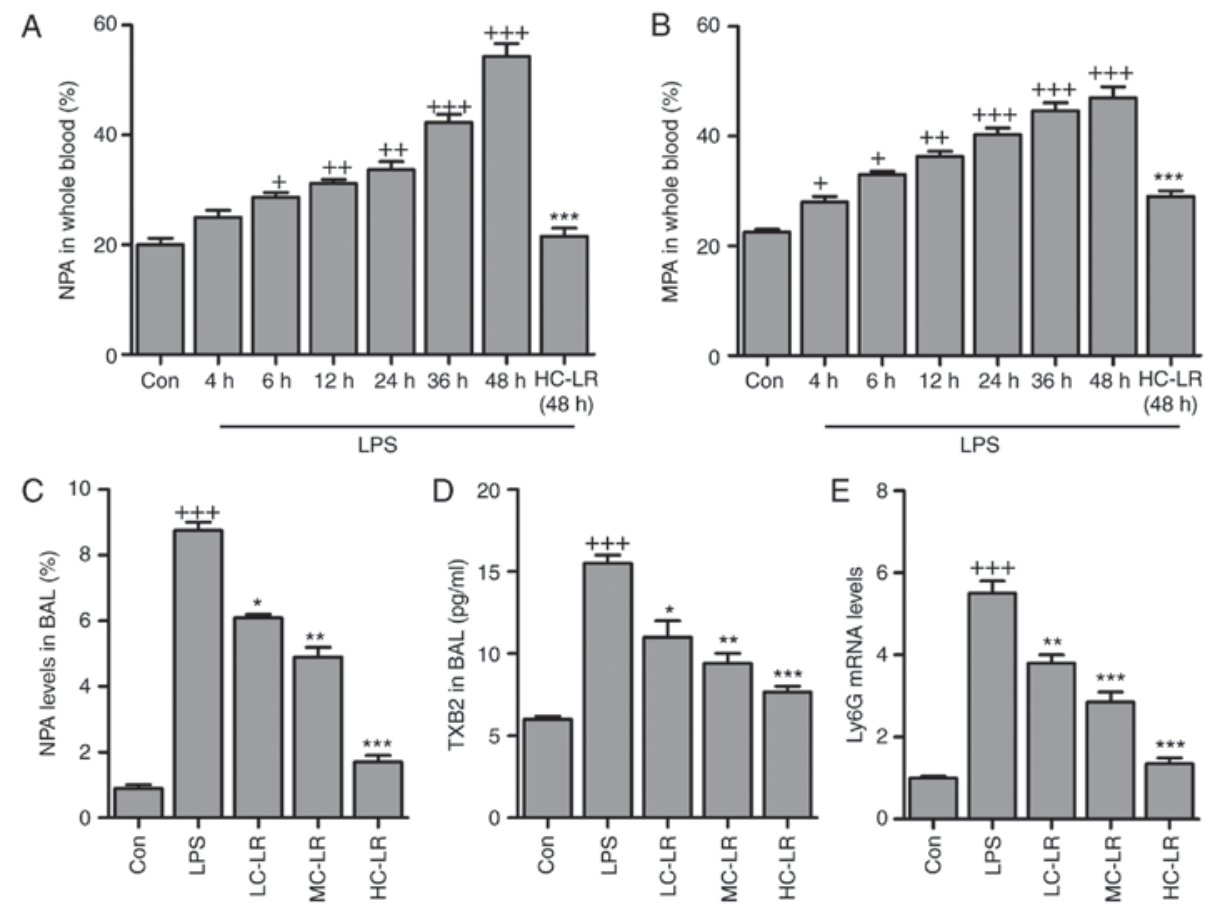

Figure 3.LR inactivates platelets in LPS-challenged mice with acute lung injury. (A) The percentage of neutrophil-platelet aggregates (NPA) and (B) percentage of monocyte-platelet aggregates (MPAs) in whole blood of mice at different time points after LPS instillation and the effects of LR treatment at described times. (C) NPA quantification and (D) TXB2 levels in BAL were measured. (E) Reverse transcription-quantitative polymerase chain reaction analysis was used to determine Ly6G expression levels in LPS-induced lung tissues of mice administered with different doses of LR. Data are represented as mean \pm standard error of the mean of three independent experiments $(\mathrm{n}=6) .{ }^{+} \mathrm{P}<0.05,{ }^{++} \mathrm{P}<0.01$ and $^{++} \mathrm{P}<0.001$ vs. the Con group in the absence of any treatments. ${ }^{*} \mathrm{P}<0.05$, ${ }^{* *} \mathrm{P}<0.01$ and $^{* * *} \mathrm{P}<0.001$ vs. the LPS groups. LR, linarin; LPS, lipopolysaccharide; Con, control; LC-LR, low concentration linarin; MC-LR, medium concentration linarin; HC-LR, high concentration linarin. NPA, neutrophil-platelet aggregates; MPAs, monocyte-platelet aggregates.

$L R$ reduces inflammation and oxidative stress by suppressing $N F-\kappa B$ and TXNIP/NLRP3 pathways in vitro. LR may be involved in ameliorating LPS-induced ALI in mice. Fig. 8A presents that pro-inflammatory cytokines TNF- $\alpha$, IL-1 $\beta$, IL-6, MCP-5, COX2, inducible nitric oxide synthase (iNOS) and MIP-1 $\alpha$ were significantly induced by LPS exposure, and in LR-pretreated groups, these cytokines were downregulated in a dose-dependent manner. IL-10 was stimulated by LPS and enhanced by LR. Western blot analysis indicated that LPS exposure stimulated IKK- $\alpha, \mathrm{I} \kappa \mathrm{B} \alpha$ and NF- $\kappa \mathrm{B}$ phosphorylation (Fig. 8B) and LR dose-dependently reduced NF- $\kappa \mathrm{B}$ pathway activation. Therefore, LR had an anti-inflammatory role in LPS-induced BEAS-2B cells.

2'-7'-Dichlorofluorescein (DCF) analysis indicated that LPS triggered high production of ROS, which was reduced by LR in a dose-dependent manner (Fig. 9A and B). In addition, in vitro, LR suppressed LPS-triggered high expression of XO and TXNIP (Fig. 9C). In addition, LR reduced NLRP3, ASC and caspase-1 protein expression induced by LPS. Finally, p38, ERK1/2 and JNK phosphorylation were enhanced by LPS treatment, and this was blunted by LR pretreatment in a dose-dependent manner (Fig. 9D).

Oxidative stress and inflammatory activity of LR depend on ROS production in LPS-treated cells. Fig. 10A indicates that LR reduced LPS- and ATP-induced ROS production compared to LPS- and ATP-single treatment groups. NAC, an ROS scavenger, reduced LPS-induced production of ROS. LR was similar to NAC in suppressing ROS generation. Fig. 10B shows that high expression of XO, TXNIP, p-p38, p-ERK1/2 and p-JNK induced by LPS were downregulated by LR following ATP addition, indicating that reducing oxidative stress-related signaling pathway expression was implicated in LR-ameliorated lung injury. In addition, LR treatment

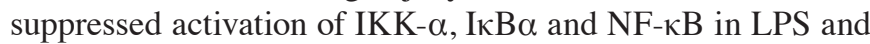
ATP co-treatment groups (Fig. 10C). Finally, pro-inflammatory cytokines TNF- $\alpha$, IL-1 $\beta$, IL-6, MCP- 5 , COX2, iNOS and MIP-1 $\alpha$ were induced by LPS exposure, and this agrees with data in Fig. 8A. Moreover, after ATP addition, the anti-inflammatory role of LR, especially at the highest dose of $40 \mu \mathrm{M}$, was observed compared to the LPS group (Fig. 10D). Thus, LR can reduce LPS-induced ROS, inhibiting inflammation and oxidative stress in human lung epithelial cells.

\section{Discussion}

ALI is an important cause of significant morbidity and mortality among patients $(1,2,30)$. The lung is continuously exposed to many inhaled infectious agents, and host-derived danger signals (31). Thus, the authors studied LPS-induced ALI in vivo and in vitro and identified inflammation and oxidative stress as significant molecular mechanisms contributing to lung injury, findings that support previous research $(5,6,32)$. Notably, LR alleviated LPS-triggered ALI via suppressing the inflammatory response and oxidative stress by inactivating NF- $\mathrm{kB}$ and TXNIP/NLRP3 signaling pathways. Therefore, LR alleviates ALI in LPS-induced mice by suppressing inflammation and oxidation.

As previously described, activated platelet function is needed in host defense, affecting the recruitment of lung neutrophils and resulting in the progression of ALI. Platelets 


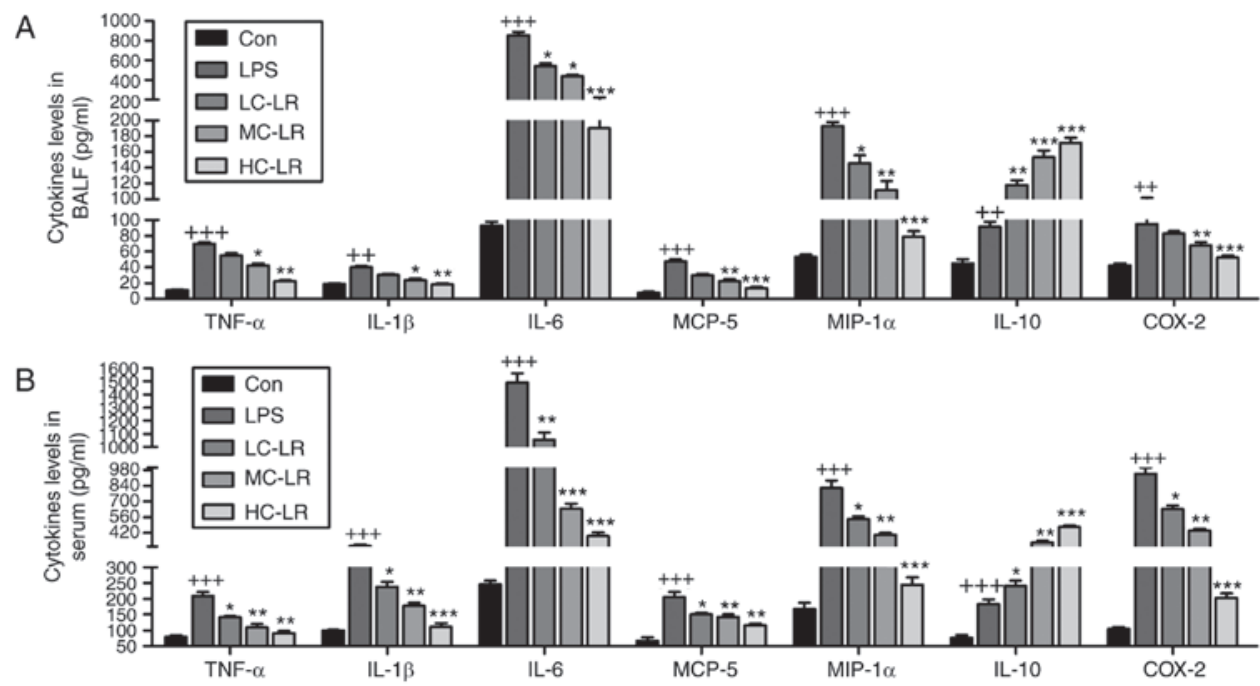

Figure 4. LR reduces LPS-induced pro-inflammatory cytokines release in BALF and serum. TNF- $\alpha$, IL-1 $\beta$, IL-6, MCP-5, MIP-1 $\alpha$, IL-10 and COX2 levels in (A) BALF and (B) serum were measured using ELISA methods. Data are represented as mean \pm standard error of the mean of three independent experiments $(\mathrm{n}=6) .{ }^{++} \mathrm{P}<0.01$ and $^{+++} \mathrm{P}<0.001$ vs. the Con group in the absence of any treatments. ${ }^{*} \mathrm{P}<0.05,{ }^{* *} \mathrm{P}<0.01$ and ${ }^{* * *} \mathrm{P}<0.001$ vs. the LPS groups. LR, linarin; LPS, lipopolysaccharide; BALF, bronchoalveolar lavage fluid; TNF- $\alpha$, tumor necrosis factor- $\alpha$; IL, interleukin; MCP-5, monocyte chemotactic protein 5; MIP-1 $\alpha$, macrophage inflammatory protein-1 $\alpha$; COX2, cyclooxygenase 2; Con, control; LC-LR, low concentration linarin; MC-LR, medium concentration linarin; HC-LR, high concentration linarin.
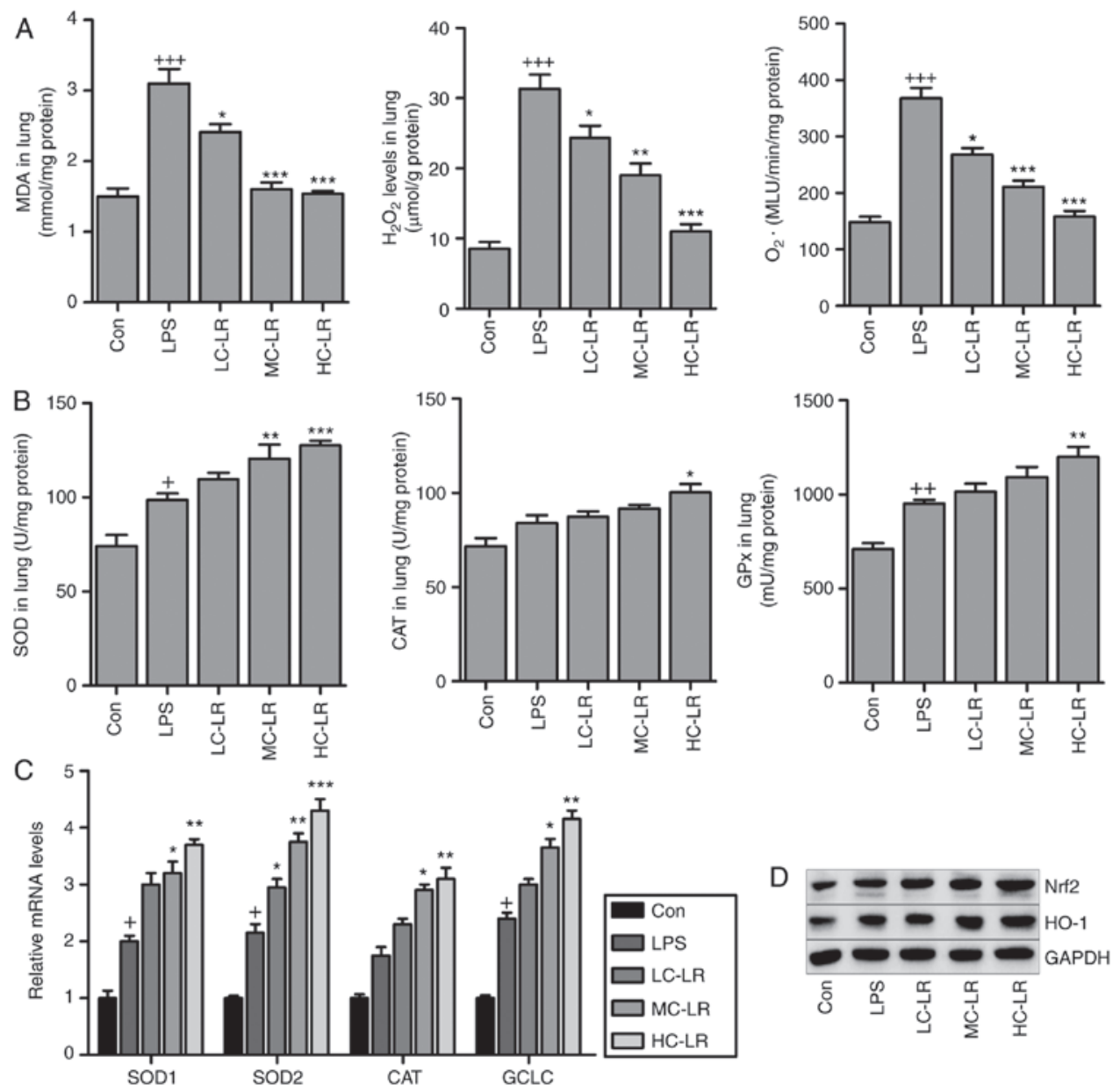

Figure 5. LR suppresses oxidative stress induced by LPS in the lung tissues of mice. (A) MDA, $\mathrm{H}_{2} \mathrm{O}_{2}$ and $\mathrm{O}_{2}$ levels in the lung tissue samples were calculated. (B) SOD activity, CAT activity, and GPx activity in the lung tissues were measured. (C) Reverse transcription-quantitative polymerase chain reaction analysis of SOD2, SOD1, CAT and glutamate-cysteine ligase (GCLC). (D) Nrf2 and heme oxygenase-1 (HO-1) expression levels were evaluated using western blot analysis. Data are represented as mean \pm standard error of the mean of three independent experiments $(\mathrm{n}=6) .{ }^{+} \mathrm{P}<0.05,{ }^{++} \mathrm{P}<0.01$ and ${ }^{++} \mathrm{P}<0.001 \mathrm{vs}$. the Con group in the absence of any treatments. ${ }^{*} \mathrm{P}<0.05,{ }^{* *} \mathrm{P}<0.01$ and $^{* * *} \mathrm{P}<0.001$ vs. the LPS groups. LR, linarin; LPS, lipopolysaccharide; MDA, malondialdehyde; SOD, superoxide dismutase; CAT, catalase; GPX, glutathione peroxidase; Nrf2, nuclear factor-erythroid 2-related factor 2; Con, control; LC-LR, low concentration linarin; MC-LR, medium concentration linarin; HC-LR, high concentration linarin. 

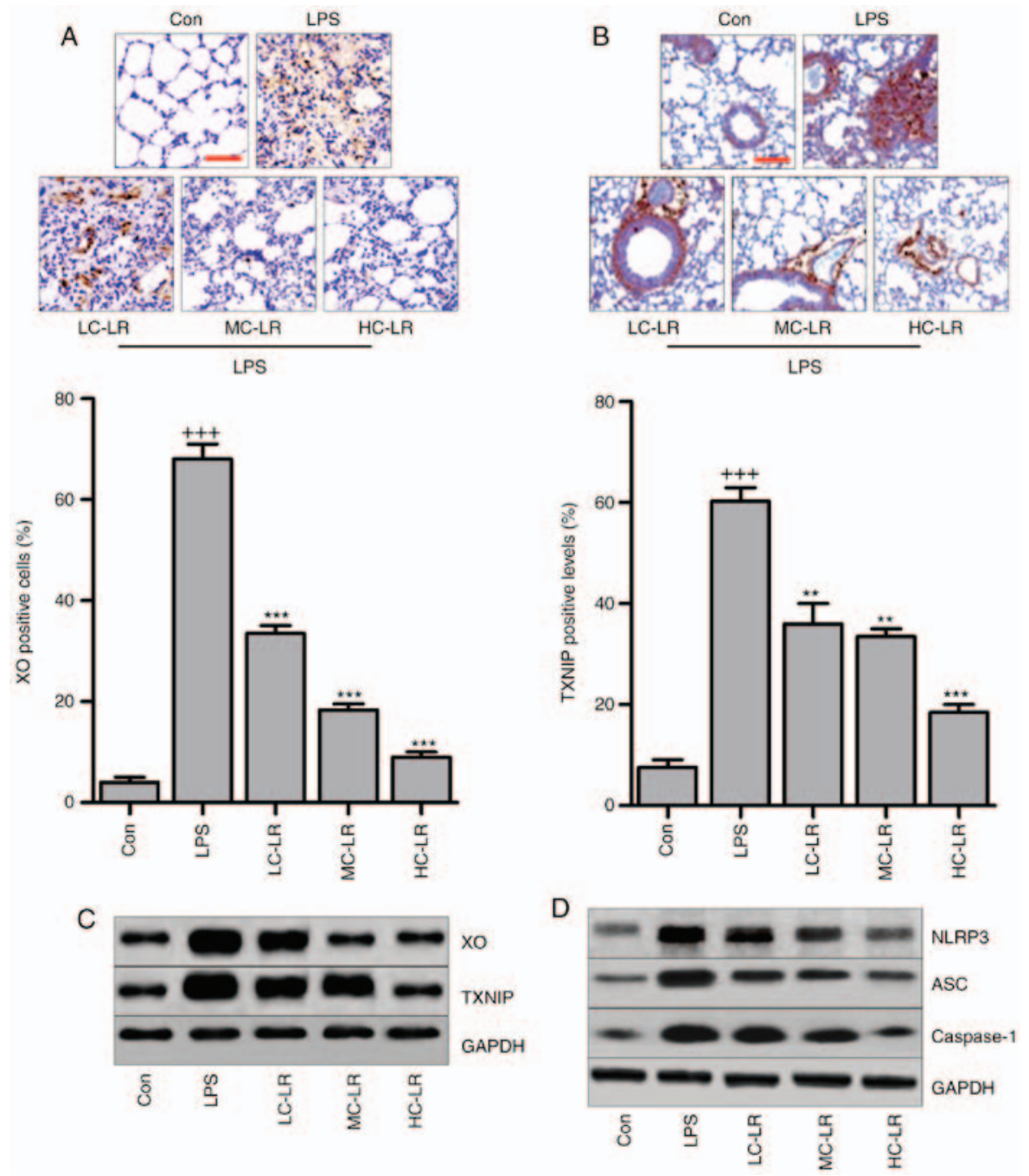

Figure 6. LR inactivates TXNIP/NLRP3 signaling pathway in the lung tissues of mice with LPS challenge. (A) xanthine oxidase (XO) and (B) TXNIP expression levels were evaluated through immunohistochemical analysis. The scale bar is $100 \mu \mathrm{m}$. (C) The immunoblotting analysis of XO and TXNIP. (D) Western blot analysis was conducted to determine NLRP3, apoptosis-associated speck-like protein containing a C-terminal caspase recruitment domain (ASC) and caspase-1 protein levels in the lung tissue samples of mice treated under various conditions. Data are represented as mean \pm standard error of the mean of three independent experiments $(\mathrm{n}=6) .{ }^{+++} \mathrm{P}<0.001$ vs. the Con group in the absence of any treatments. ${ }^{* *} \mathrm{P}<0.01$ and ${ }^{* * *} \mathrm{P}<0.001$ vs. the LPS groups. LR, linarin; LPS, lipopolysaccharide; XO, xanthine oxidase; Con, control; LC-LR, low concentration linarin; MC-LR, medium concentration linarin; HC-LR, high concentration linarin.

become activated at inflammatory sites and adhere to other platelets and leukocytes, forming NPAs or MPAs at exposed endothelia. NPAs are formed in the lung microcirculation and rise in blood and alveolar compartments after injury (33). Thus, circulating leukocyte-platelet aggregates are a marker of platelet activation, and has been reported in patients with inflammatory conditions, such as sepsis, rheumatoid arthritis, coronary diseases, cystic fibrosis, inflammatory bowel disease and acute respiratory distress syndrome (34). Thromboxane A2, an indicator of platelet activation, is rapidly hydrolyzed to the inactive stable metabolite, TXB2 (24). CD41 is a specific platelet marker $(23,35)$. The authors reported that LPS-induced increases in CD41, NPAs, MPAs and TXB2 were downregulated by LR, suggesting that LR treatment could inhibit platelet activation, and perhaps reverse ALI.

Neutrophils and macrophages are chief inflammatory mediators during progression of ALI (36). They infiltrate into lung tissues and release enzymes and phagocytize pathogens. These inflammatory cells are a fundamental source of inflammatory regulators in vivo. In LPS-mediated inflammation, neutrophils and macrophages are activated and recruited to the inflammatory site $(37,38)$. Lymphocytes have also been implicated in the progression of ALI $(39,40)$. In the current study, the authors confirmed that LPS increased these inflammatory cells, evidence of ALI establishment in rodents. Importantly, LR reduced macrophages, neutrophils and lymphocytes to alleviate ALI.

Oversecretion of pro-inflammatory cytokines, including IL-1 $\beta$, TNF- $\alpha$, IL-6, MCP-5 and MIP- $1 \alpha$, is key to the inflammatory response (41). Data show that inhibiting multiple inflammatory regulators may attenuate injury in animals (42). Inflammatory cytokines can amplify the inflammatory response by augmenting secretion of chemoattractant factors by airway epithelial cells and alveolar macrophages, as well as through expression of adhesion molecules via epithelial cells and leukocytes (43). Activation of the NF- $\kappa$ B pathway regulated by IKK- $\alpha$ and I $\mathrm{KB} \alpha$ is essential for regulating release of pro-inflammatory cytokines (44). In the present study, the authors found that LR possesses anti-inflammatory ability, supported by reduced TNF- $\alpha$, IL-1 $\beta$, IL-6, MCP-5 
A

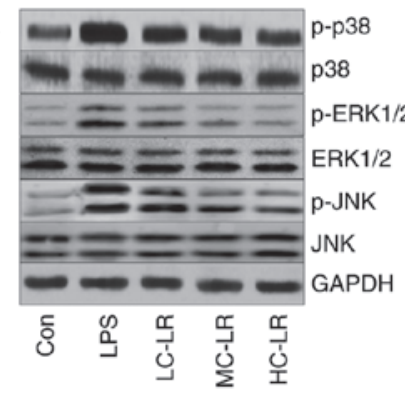

$\mathrm{B}$

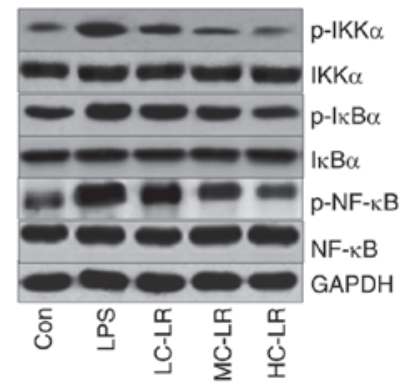

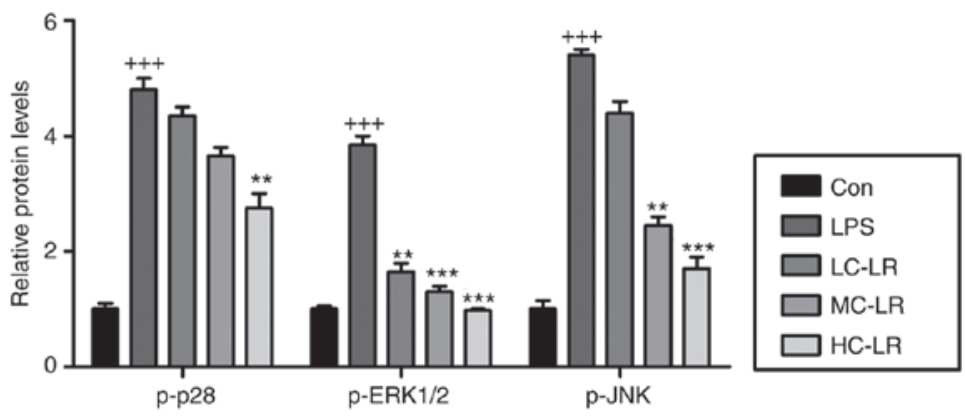

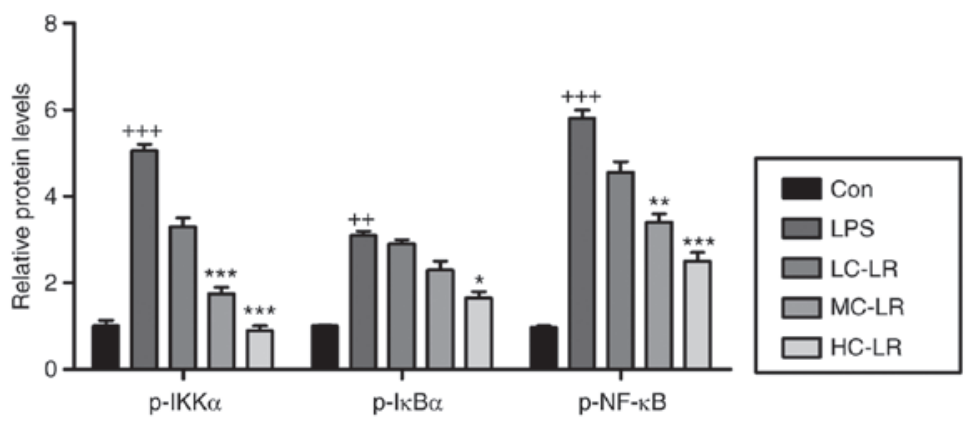

Figure 7. LR blocks mitogen-associated protein kinase and NF-kB pathways in LPS-induced mice with ALI. (A) Phosphorylated p38, phosphorylated ERK1/2

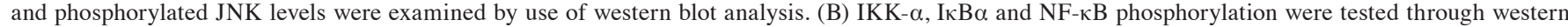
blot analysis. Data are represented as mean \pm standard error of the mean of three independent experiments $(\mathrm{n}=6) .{ }^{++} \mathrm{P}<0.01$ and ${ }^{+++} \mathrm{P}<0.001 \mathrm{vs}$. the Con

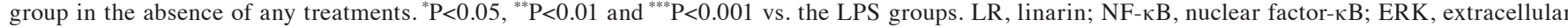
signal-regulated kinase; JNK, c-Jun N-terminal kinase; IKK- $\alpha$, IкB kinase- $\alpha$; Con, control; LC-LR, low concentration linarin; MC-LR, medium concentration linarin; HC-LR, high concentration linarin.
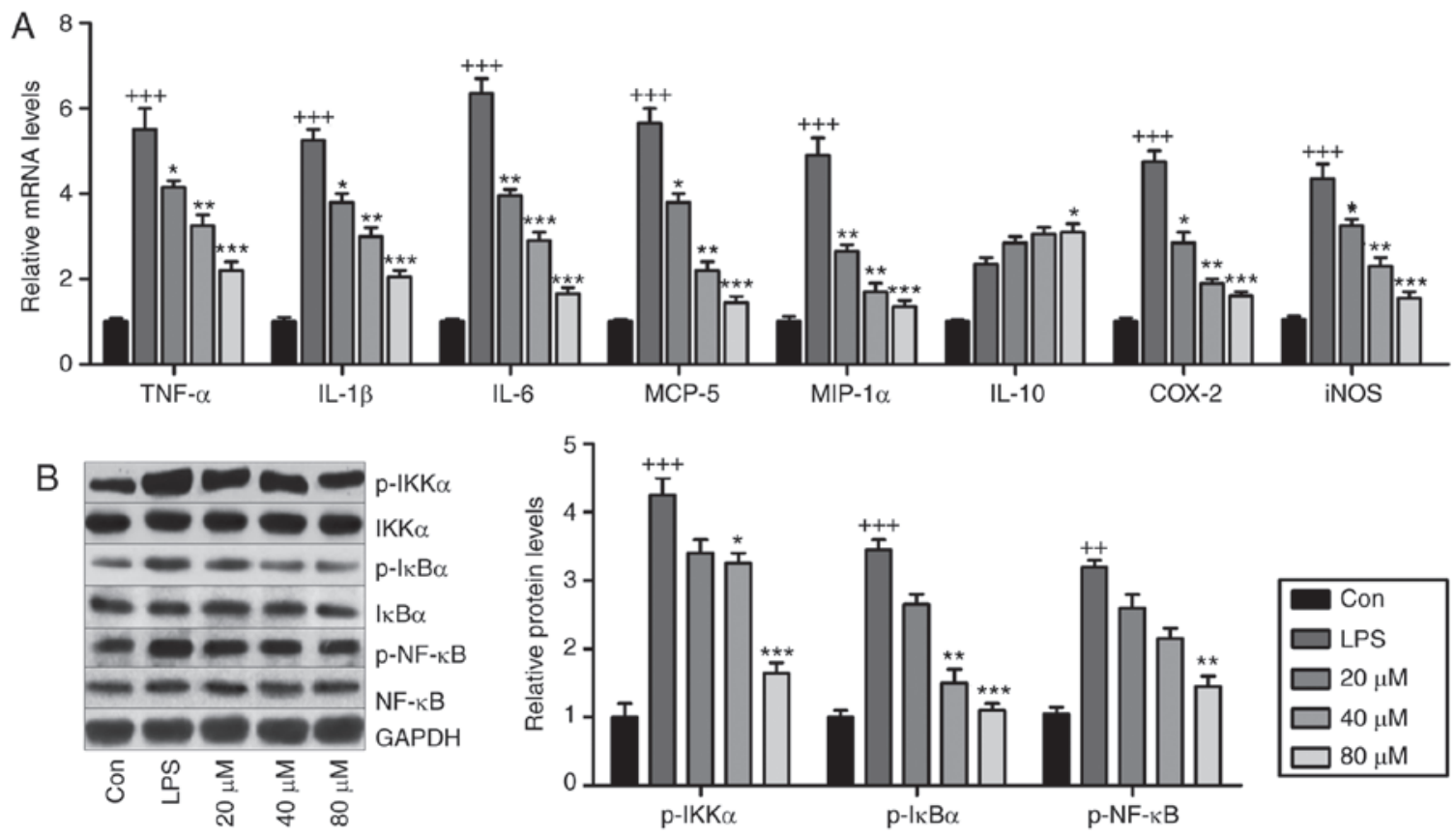

Figure 8. LR reduces inflammation through suppressing the NF- $\mathrm{kB}$ pathway in vitro. The lung epithelia cells of BEAS-2B were pretreated with different concentrations of LR $(0,20,40$ and $80 \mu \mathrm{M})$ for $24 \mathrm{~h}$, followed by LPS exposure for another $1 \mathrm{~h}$. Then, all cells were harvested for the following research. (A) TNF- $\alpha$, IL-1 $\beta$, IL-6, MCP-5, MIP-1 $\alpha$, IL-10, iNOS and COX2 gene levels in cells treated under various conditions were measured using Reverse transcription-quantitative poly-

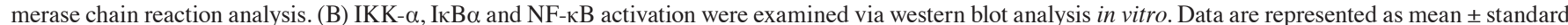
error of the mean of three independent experiments $(n=6) .{ }^{+} \mathrm{P}<0.05,{ }^{++} \mathrm{P}<0.01$ and ${ }^{+++} \mathrm{P}<0.001$ vs. the Con group in the absence of any treatments. ${ }^{*} \mathrm{P}<0.05,{ }^{* *} \mathrm{P}<0.01$ and ${ }^{* * *} \mathrm{P}<0.001$ vs. the LPS groups. LR, linarin; NF- $\mathrm{kB}$, nuclear factor- $\kappa \mathrm{B}$; LPS, lipopolysaccharide; TNF- $\alpha$, tumor necrosis factor- $\alpha$; IL, interleukin; MCP-5, monocyte chemotactic protein 5 ; MIP-1 $\alpha$, macrophage inflammatory protein-1 $\alpha$; iNOS, inducible nitric oxide synthase; COX2, cyclooxygenase 2; Con, control.

and MIP-1 $\alpha$, and de-phosphorylated IKK- $\alpha, \operatorname{I\kappa B} \alpha$ and $\mathrm{NF}-\kappa \mathrm{B}$. IL-10, in contrast, is a potent anti-inflammatory molecule and suppresses the action of many pro-inflammatory molecules (45). Consistently, LR enhanced downregulation of IL-10 induced by LPS, confirming its anti-inflammatory capability. 
A
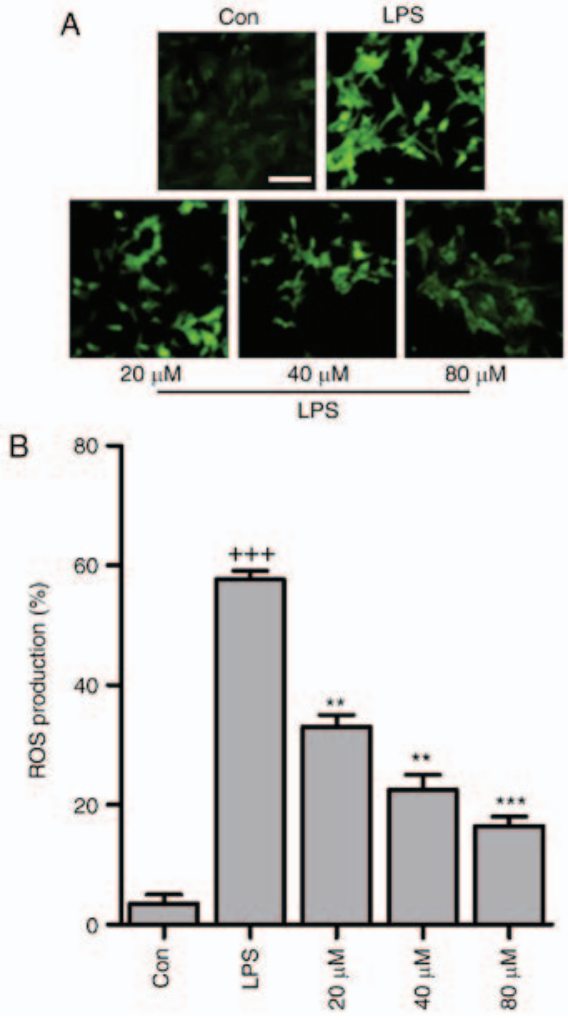

C

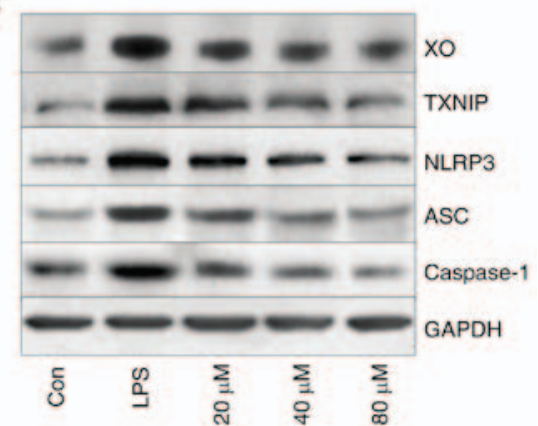

D

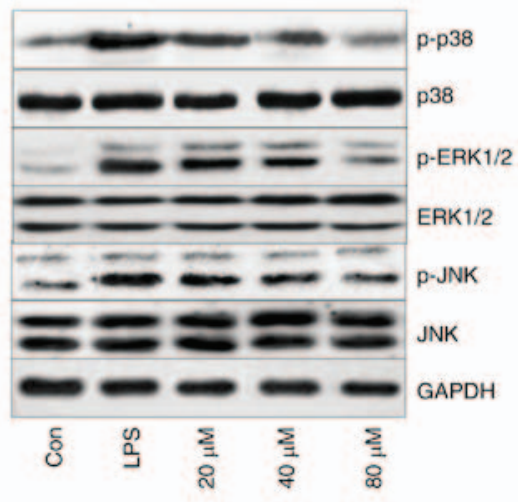

Figure 9. LR reduces oxidative stress through suppressing the TXNIP/NLRP3 pathway in LPS-treated cells. The lung epithelia cells of BEAS-2B were pretreated with different concentrations of LR $(0,20,40$ and $80 \mu \mathrm{M})$ for $24 \mathrm{~h}$, followed by LPS exposure for $1 \mathrm{~h}$. Then, all cells were harvested for the following research. (A) 2'-7'-Dichlorofluorescein (DCF) analysis was used to calculate ROS generation, and the representative images were displayed. The scale bar is $50 \mu \mathrm{m}$. (B) The quantification of ROS production was exhibited. (C) Western blot analysis of XO, TXNIP, LPRP3, apoptosis-associated speck-like protein containing a C-terminal caspase recruitment domain (ASC) and caspase-1 in LPS-treated cells in the presence or absence of LR. (D) p-p38, p-ERK1/2 and $\mathrm{p}-\mathrm{JNK}$ levels were measured through western blot analysis. Data are represented as mean \pm standard error of the mean of three independent experiments $(\mathrm{n}=6)$. ${ }^{++} \mathrm{P}<0.001$ vs. the Con group in the absence of any treatments. ${ }^{* *} \mathrm{P}<0.01$ and ${ }^{* * *} \mathrm{P}<0.001$ vs. the LPS groups. LR, linarin; LPS, lipopolysaccharide; XO, xanthine oxidase; ERK, extracellular signal-regulated kinase; JNK, c-Jun N-terminal kinase; ROS, reactive oxygen species; Con, control.
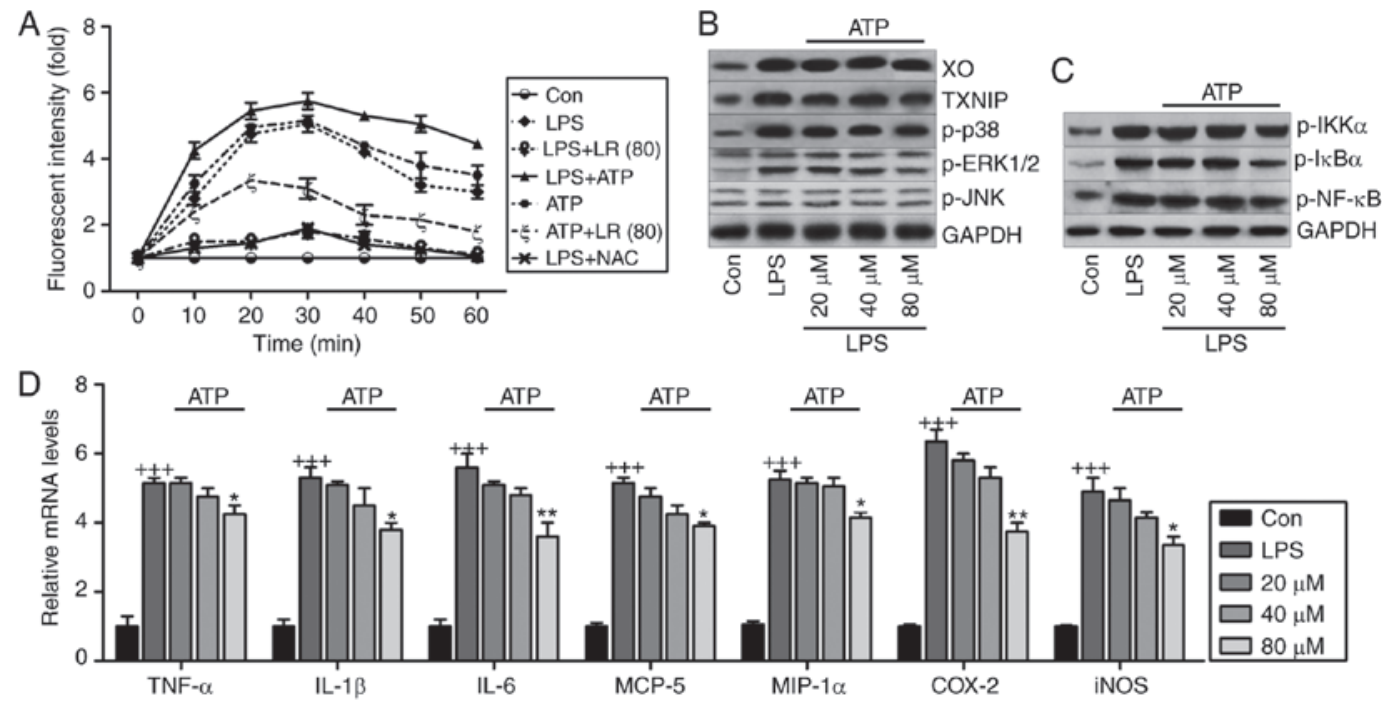

Figure 10. ROS production is involved in LR-reduced oxidative stress and inflammation in LPS-treated cells. (A) The lung epithelia cells of BEAS-2B were pretreated with LR $(80 \mu \mathrm{M})$ for $24 \mathrm{~h}$, followed by LPS exposure for another $1 \mathrm{~h}$, and then for addition of $10 \mathrm{mM} \mathrm{N}$-acetylcysteine (NAC) or $5 \mathrm{mM}$ ATP for 0-60 min as indicated. Then, reactive oxygen species production was measured as the relative fluorescence intensity. The lung epithelia cells of BEAS-2B were pretreated with different concentrations of LR $(0,20,40$ and $80 \mu \mathrm{M})$ for $24 \mathrm{~h}$, followed by LPS exposure for another $1 \mathrm{~h}$, and then for addition of $5 \mathrm{mM}$ ATP for 60 min. Finally, all cells were harvested for further experiments. (B) XO, TXNIP, p-p38, p-ERK1/2 and p-JNK protein levels were measured using

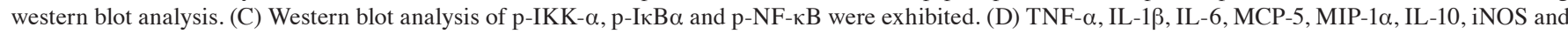
COX2 gene levels were evaluated using reverse transcription-quantitative polymerase chain reaction assays. Data are represented as mean \pm standard error of the mean of three independent experiments $(\mathrm{n}=6) .{ }^{+++} \mathrm{P}<0.001$ vs. the Con group in the absence of any treatments. ${ }^{*} \mathrm{P}<0.05$, and ${ }^{* * *} \mathrm{P}<0.01$ vs. the LPS groups. LR, linarin; LPS, lipopolysaccharide; XO, xanthine oxidase; ERK, extracellular signal-regulated kinase; JNK, c-Jun N-terminal kinase; IKK- $\alpha$, IкB kinase- $\alpha$; TNF- $\alpha$, tumor necrosis factor- $\alpha$; IL, interleukin; MCP-5, monocyte chemotactic protein 5; MIP-1 $\alpha$, macrophage inflammatory protein-1 $\alpha$; iNOS, inducible nitric oxide synthase; COX2, cyclooxygenase 2; Con, control. 
Disturbance of oxidative stress is noted in LPS-induced ALI $(46,47)$. LPS can potentiate $\mathrm{XO}$ to generate ROS, including $\mathrm{H}_{2} \mathrm{O}_{2}$ and $\mathrm{O}_{2} \cdot(48)$. LPS-treatment enhanced XO, elevated $\mathrm{H}_{2} \mathrm{O}_{2}$, $\mathrm{O}_{2} \cdot$ and MDA, important products of ROS. LR administration decreased $\mathrm{XO}, \mathrm{H}_{2} \mathrm{O}_{2}$ and $\mathrm{O}_{2} \cdot \mathrm{SOD}, \mathrm{CAT}$ and GPx are major scavengers of ROS, and their activity was decreased in LPS-treated tissues. Constitutive Nrf2 expression is important for sustaining normal redox balance, and it is induced in response to oxidative stress, with subsequent transcription of cyto-protective genes; it is an essential defense against oxidative stress (49). LR induced the expression of Nrf2, and the downstream HO-1 protein in LPS-induced lung tissues, indicating its antioxidant ability. TXNIP binding to NLRP3 has been implicated various diseases (50) and NLRP3 inflammasome activation was observed in ALI (51). In the present study, the NLRP3 inflammasome was activated in LPS-induced tissues and cells, as was its downstream signals of ASC and caspase-1, paralleling IL-1 $\beta$ production and exacerbating lung injury. Furthermore, the TXNIP/NLRP3 signaling pathway has been implicated in oxidative stress $(52,53)$. As previously described, activation of MAPK, including p38, ERK1/2 and JNK, aggravates oxidative stress and injury in lungs $(29,54)$. Then, ROS generation activates MAPK expression (55). In the current study, the authors found that LR administration reduced TXNIP/NLRP3 expression and MAPK phosphorylation in LPS-treated samples. Additionally, ATP treatment combined with LPS in vitro

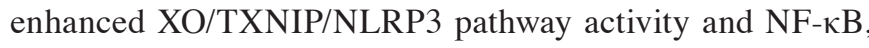
accelerating cell injury. However, increased ROS induced by ATP in LPS-treated cells were reduced by LR, which downregulated ROS production. Therefore, LR can suppress lung injury in mice, which might be associated with reduced ROS, subsequently reducing inflammation and oxidative stress.

In conclusion, LPS exacerbated inflammation, oxidative stress and lung injury in mice by activating NF- $\mathrm{KB}$, XO/TXNIP/NLRP3 and MAPK pathways and LR scavenged ROS reduced the inflammatory response and oxidative stress

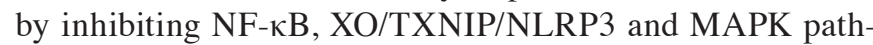
ways. Thus, LR may have promise for treating ALI.

\section{Acknowledgements}

The authors thank Dr Yinghui Kong and Dr haoguang Wang (Nanjing Medical University, Nanjing, China) for their technical support.

\section{Funding}

No funding was received.

\section{Availability of data and materials}

All data generated or analyzed during this study are included in this published article.

\section{Authors' contributions}

$\mathrm{XH}$ and SG made substantial contributions to the conception and design of the present study. XH, YW, MM, QS and HS performed the experiments. XH wrote the paper. SG edited and revised the manuscript critically for important intellectual content. All authors read and approved the manuscript and agree to be accountable for all aspects of the research in ensuring that the accuracy or integrity of any part of the work are appropriately investigated and resolved.

\section{Ethics approval and consent to participate}

All experimental protocols were approved by the Institutional Review Board of the Huai'an First People's Hospital, Nanjing Medical University (Nanjing, China).

\section{Patient consent for publication}

Not applicable.

\section{Competing interests}

The authors declare that they have no competing interests.

\section{References}

1. ARDS Definition Task Force; Ranieri VM, Rubenfeld GD, Thompson BT, Ferguson ND, Caldwell E, Fan E, Camporota L and Slutsky AS: Acute respiratory distress syndrome: The Berlin Definition. JAMA 307: 2526-2533, 2012.

2. Matthay MA and Zemans RL: The acute respiratory distress syndrome: Pathogenesis and treatment. Annu Rev Pathol 6: 147-163, 2011.

3. Li B, Yang J, Huang Q, Zhang Yi, Peng C, Zhang Y, He Y, Shi J, Li W, Hu J and Fan C: Biodistribution and pulmonary toxicity of intratracheally instilled graphene oxide in mice. NPG Asia Materials 5: e44, 2013.

4. Spragg RG, Bernard GR, Checkley W, Curtis JR, Gajic O, Guyatt G, Hall J, Israel E, Jain M, Needham DM, et al: Beyond mortality: Future clinical research in acute lung injury. Am J Respir Crit Care Med 181: 1121-1127, 2010.

5. Bouwmeester T, Bauch A, Ruffner H, Angrand PO, Bergamini G, Croughton K, Cruciat C, Eberhard D, Gagneur J, Ghidelli S, et al: A physical and functional map of the human TNF-alpha/NF-kappa B signal transduction pathway. Nat Cell Biol 6: 97-105, 2004.

6. Bhatia $\mathrm{M}$ and Moochhala S: Role of inflammatory mediators in the pathophysiology of acute respiratory distress syndrome. J Pathol 202: 145-156, 2004.

7. Guzel A, Kanter M,Pergel A and Erboga M: Anti-inflammatory and antioxidant effects of infliximab on acute lung injury in a rat model of intestinal ischemia/reperfusion. J Mol Histol 43: 361-369, 2012.

8. Mao X, Yu CR, Li WH and Li WX: Induction of apoptosis by shikonin through a ROS/JNK-mediated process in Bcr/Abl-positive chronic myelogenous leukemia (CML) cells. Cell Res 18: 879-888, 2008

9. Zhou J and Chng WJ: Roles of thioredoxin binding protein (TXNIP) in oxidative stress, apoptosis and cancer. Mitochondrion 13: 163-169, 2013.

10. Jiao R, Liu Y, Gao H, Xiao J and So KF: The anti-oxidant and antitumor properties of plant polysaccharides. Am J Chin Med 44: 463-488, 2016.

11. Yang CS, Shin DM and Jo EK: The role of NLR-related protein 3 inflammasome in host defense and inflammatory diseases. Int Neurourol J 16: 2-12, 2012.

12. Sun X, Jiao X, Ma Y, Liu Y, Zhang L, He Y and Chen Y: Trimethylamine $\mathrm{N}$-oxide induces inflammation and endothelial dysfunction in human umbilical vein endothelial cells via activating ROS-TXNIP-NLRP3 inflammasome. Biochem Biophys Res Commun 481: 63-70, 2016.

13. Rajamäki K, Lappalainen J, Oörni K, Välimäki E, Matikainen S, Kovanen PT and Eklund KK: Cholesterol crystals activate the NLRP3 inflammasome in human macrophages: A novel link between cholesterol metabolism and inflammation. PLoS One 5: e11765, 2010

14. Guan J, Wu X, Arons E and Christou H: The p38 mitogen-activated protein kinase pathway is involved in the regulation of heme oxygenase- 1 by acidic extracellular $\mathrm{pH}$ in aortic smooth muscle cells. J Cell Biochem 105: 1298-1306, 2008. 
15. Kim YH, Lee YS and Choi EM: Linarin isolated from Buddleja officinalis prevents hydrogen peroxide-induced dysfunction in osteoblastic MC3T3-E1 cells. Cell Immunol 268: 112-116, 2011.

16. Suh KS, Rhee SY, Jung WW, Kim NJ, Jang YP, Kim HJ, Kim MK, Choi YK and Kim YS: Chrysanthemum zawadskii extract protects osteoblastic cells from highly reducing sugar-induced oxidative damage. Int J Mol Med 32: 241-250, 2013.

17. Qiaoshan Y, Suhong C, Minxia S, Wenjia M, Bo L and Guiyuan L: Preparative purification of linarin extracts from Dendranthema indicum flowers and evaluation of its antihypertensive effect. Evid Based Complement Alternat Med 2014: 394276, 2014

18. Han S, Sung KH, Yim D, Lee S, Lee CK, Ha NJ and Kim K: The effect of linarin on LPS-induced cytokine production and nitric oxide inhibition in murine macrophages cell line RAW264.7. Arch Pharm Res 25: 170-177, 2002.

19. Yu Q, Li X and Cao X: Linarin could protect myocardial tissue from the injury of Ischemia-reperfusion through activating $\mathrm{Nrf}-2$ Biomed Pharmacoth 90: 1-7, 2017.

20. Livak KJ and Schmittgen TD: Analysis of relative gene expression data using real-time quantitative PCR and the 2(-Delta Delta C(T)) method. Methods 25: 402-408, 2001.

21. Kunapuli SP, Dorsam RT, Kim S and Quinton TM: Platelet purinergic receptors. Curr Opin Pharmacol 3: 175-180, 2003.

22. Cho MS, Bottsford-Miller J, Vasquez HG, Stone R, Zand B Kroll MH, Sood AK and Afshar-Kharghan V: Platelets increase the proliferation of ovarian cancer cells. Blood 120: 4869-4872, 2012.

23. Guo Y, Mishra A, Howland E, Zhao C, Shukla D, Weng T and Liu L: Platelet-derived Wnt antagonist Dickkopf-1 is implicated in ICAM-1/VCAM-1-mediated neutrophilic acute lung inflammation. Blood 126: 2220-2229, 2015.

24. Wang L, Sammani S, Moreno-Vinasco L, Letsiou E, Wang T, Camp SM, Bittman R, Garcia JG and Dudek SM: FTY720(s)-phosphonate preserves sphingosine 1-phosphate receptor 1 expression and exhibits superior barrier protection to FTY720 in acute lung injury. Criti Care Med 42: e189-e199, 2014

25. Chen T, Mou Y, Tan J, Wei L, Qiao Y, Wei T, Xiang P, Peng S, Zhang Y, Huang Z and Ji $\mathrm{H}$ : The protective effect of CDDO-Me on lipopolysaccharide-induced acute lung injury in mice. Int Immunopharmaco 25: 55-64, 2015.

26. Camicia G, Pozner R and de Larrañaga G: Neutrophil extracellular traps in sepsis. Shock 42: 286-294, 2014.

27. Chabot F, Mitchell JA, Gutteridge JM and Evans TW: Reactive oxygen species in acute lung injury. Eur Respir J 11: 745-757, 1998 .

28. Abais JM, Xia M, Zhang Y, Boini KM and Li PL: Redox regulation of NLRP3 inflammasomes: ROS as trigger or effector? Antioxid Redox Sign 22: 1111-1129, 2015.

29. Chiu WH, Luo SJ, Chen CL, Cheng JH, Hsieh CY, Wang CY, Huang WC, Su WC and Lin CF: Vinca alkaloids cause aberran ROS-mediated JNK activation, Mcl-1 downregulation, DNA damage, mitochondrial dysfunction, and apoptosis in lung adenocarcinoma cells. Biochem Pharmacol 83: 1159-1171, 2012.

30. Kim HA, Park JH, Lee S, Choi JS, Rhim T and Lee M: Combined delivery of dexamethasone and plasmid DNA in an animal model of LPS-induced acute lung injury. J Control Release 156: 60-69, 2011.

31. Wen HL, Liang ZS, Zhang R and Yang K: Anti-inflammatory effects of triptolide improve left ventricular function in a rat model of diabetic cardiomyopathy. Cardiovasc Diabetol 12: 50, 2013

32. Ben DF, Yu XY, Ji GY, Zheng DY, Lv KY, Ma B, and Xia ZF: TLR4 mediates lung injury and inflammation in intestinal ischemia-reperfusion. J Surg Res 174: 326-333, 2012.

33. Alım Z, Kılınç N, İsgör MM, Sengül B and Beydemir S: Some anti-inflammatory agents inhibit esterase activities of human carbonic anhydrase isoforms I and II: An in vitro study. Chem Biology Drug Des 86: 857-863, 2015.

34. Dopheide JF, Rubrech J, Trumpp A, Geissler P, Zeller GC, Bock K, Dünschede F, Trinh TT, Dorweiler B, Münzel T, et al: Leukocyte-platelet aggregates-a phenotypic characterization of different stages of peripheral arterial disease. Platelets 27 : 658-667, 2016

35. Hu L, Du L, Zhao Y, Li W, Ouyang Q, Zhou D, Lu G and Lin G: Modeling Glanzmann thrombasthenia using patient specific iPSCs and restoring platelet aggregation function by CD41 overexpression. Stem Cell Res 20: 14-20, 2017.

36. Park DW, Jiang S, Liu Y, Siegal GP, Inoki K, Abraham E and Zmijewski JW: GSK3 $\beta$-dependent inhibition of AMPK potentiates activation of neutrophils and macrophages and enhances severity of acute lung injury. Am J Physiol Lung Cell Mol Physiol 307: L735-L745, 2014.
37. Bellac CL, Dufour A, Krisinger MJ, Loonchanta A, Starr AE, Auf dem Keller U, Lange PF, Goebeler V, Kappelhoff R, Butler GS, et al: Macrophage matrix metalloproteinase-12 dampens inflammation and neutrophil influx in arthritis. Cell Rep 9: 618-632, 2014.

38. Nguyen KD, Fentress SJ, Qiu Y, Yun K, Cox JS and Chawla A: Circadian gene Bmall regulates diurnal oscillations of Ly6Chi inflammatory monocytes. Science 341: 1483-1488, 2013.

39. WangJ,Liu YT,XiaoL,ZhuL,WangQand YanT:Anti-inflammatory effects of apigenin in lipopolysaccharide-induced inflammatory in acute lung injury by suppressing COX-2 and NF- $\mathrm{BB}$ pathway. Inflammation 37: 2085-2090, 2014.

40. Natarajan V, Dudek SM, Jacobson JR, Moreno-Vinasco L, Huang LS, Abassi T, Mathew B, Zhao Y, Wang L, Bittman R, et al Sphingosine-1-phosphate, FTY720, and sphingosine-1-phosphate receptors in the pathobiology of acute lung injury. Am J Respir Cell Mol Biol 49: 6-17, 2013.

41. Tristan M, Orozco LJ, Steed A, Ramírez-Morera A and Stone P: Mifepristone for uterine fibroids. Cochrane Database Syst Rev 8: CD007687, 2012

42. Yousef AA, Amr YM and Suliman GA: The diagnostic value of serum leptin monitoring and its correlation with tumor necrosis factor-alpha in critically ill patients: A prospective observational study. Crit Care 14: R33, 2010.

43. Eickmeier O, Seki H, Haworth O, Hilberath JN, Gao F, Uddin M, Croze RH, Carlo T, Pfeffer MA and Levy BD: Aspirin-triggered resolvin D1 reduces mucosal inflammation and promotes resolution in a murine model of acute lung injury. Mucosal Immunol 6 : 256-266, 2013

44. Ganeff C, Remouchamps C, Boutaffala L, Benezech C, Galopin G, Vandepaer S, Bouillenne F, Ormenese S, Chariot A, Schneider P, et al: Induction of the alternative NF- $\kappa \mathrm{B}$ pathway by lymphotoxin $\alpha \beta(\mathrm{LT} \alpha \beta)$ relies on internalization of LT $\beta$ receptor. Mol Cell Biol 31: 4319-4334, 2011.

45. Akdis CA and Blaser K: Mechanisms of interleukin-10-mediated immune suppression. Immunology 103: 131-136, 2001.

46. Lee JH, Jo YH, Kim K, Lee JH, Rim KP, Kwon WY, Suh GJ and Rhee JE: Effect of N-acetylcysteine (NAC) on acute lung injury and acute kidney injury in hemorrhagic shock. Resuscitation 84 121-127, 2013.

47. Zhao W, Gan X, Su G, Wanling G, Li S, Hei Z, Yang C and Wang H: The interaction between oxidative stress and mast cell activation plays a role in acute lung injuries induced by intestina ischemia-reperfusion. J Surg Res 187: 542-552, 2014.

48. Miura D, Miura Y, Yagasaki K. Resveratrol inhibits hepatoma cell invasion by suppressing gene expression of hepatocyte growth factor via its reactive oxygen species-scavenging property. Clin Exp Metastasis 21: 445-451, 2004

49. Kovac S, Angelova PR, Holmström KM, Zhang Y, Dinkova-Kostova AT and Abramov AY: Nrf2 regulates ROS production by mitochondria and NADPH oxidase. Biochim Biophys Acta 1850: 794-801, 2015

50. Abais JM, Xia M, Li G, Chen Y, Conley SM, Gehr TW, Boini KM and Li PL: Nod-like receptor protein 3 (NLRP3) inflammasome activation and podocyte injury via thioredoxin-interacting protein (TXNIP) during hyperhomocysteinemia. J Biol Chem 289 27159-27168, 2014

51. Zhang B, Wang B, Cao S, Wang Y and Wu D: Silybin attenuates LPS-induced lung injury in mice by inhibiting $N F-\kappa B$ signaling and NLRP3 activation. Int J Mol Med 39: 1111-1118, 2017.

52. Li Y, Li J, Li S, Li Y, Wang X, Liu B, Fu Q and Ma S: Curcumin attenuates glutamate neurotoxicity in the hippocampus by suppression of ER stress-associated TXNIP/NLRP3 inflammasome activation in a manner dependent on AMPK. Toxicol Appl Pharm 286: 53-63, 2015

53. Liu W, Gu J, Qi J, Zeng XN, Ji J, Chen ZZ and Sun XL: Lentinan exerts synergistic apoptotic effects with paclitaxel in A549 cells via activating ROS-TXNIP-NLRP3 inflammasome. J Cell Mol Med 19: 1949-1955, 2015.

54. Fielhaber JA, Carroll SF, Dydensborg AB, Shourian M, Triantafillopoulos A, Harel S, Hussain SN, Bouchard M, Qureshi ST and Kristof AS: Inhibition of mammalian target of rapamycin augments lipopolysaccharide-induced lung injury and apoptosis. J Immunol 188: 4535-4542, 2012.

55. Chen J, Guo R, Yan H, Tian L, You Q, Li S, Huang R and Wu K: Naringin inhibits ROS-activated MAPK pathway in high glucose-induced injuries in $\mathrm{H} 9 \mathrm{c} 2$ cardiac cells. Basic Clin Pharmacol Toxicol 114: 293-304, 2014.

This work is licensed under a Creative Commons

Attribution-NonCommercial-NoDerivatives 4.0 International (CC BY-NC-ND 4.0) License. 